\title{
Intra-specific variation and allometry of the skull of Late Cretaceous side-necked turtle Bauruemys elegans (Pleurodira, Podocnemididae) and how to deal with morphometric data in fossil vertebrates
}

\author{
Thiago F. Mariani ${ }^{\text {Corresp., }}{ }^{1}$, Pedro S. R. Romano ${ }^{1}$ \\ 1 Deparatamento de Biologia Animal, Universidade Federal de Viçosa, Viçosa, MG, Brazil \\ Corresponding Author: Thiago F. Mariani \\ Email address: tmariani.bio@gmail.com
}

Background. Previous quantitative studies on Bauruemys elegans (Suárez, 1969) shell variation, as well as the taphonomic interpretation of its type locality, have suggested that all specimens collected in this locality may have belonged to the same population. We rely on this hypothesis in a morphometric study of the skull. Also, we tentatively assessed the eating preference habits differentiation that might be explained as due to ontogenetic changes. Methods. We carried out an ANOVA testing 29 linear measurements from 21 skulls of $B$. elegans taken by using a caliper and through images, using the ImageJ software. A Principal Components Analysis (PCA) was performed with 27 measurements (excluding total length and width characters; =raw data) in order to visualize the scatter plots based on the form variance only. Then, a PCA was carried out using ratios of length and width of each original measurement to assess shape variation among individuals. Finally, original measurements were log-transformed to describe allometries over ontogeny. Results. No statistical differences were found between caliper and ImageJ measurements. The first three PCs of the PCA with raw data comprised $70.2 \%$ of the variance. PC1 was related to size variation and all others related to shape variation. Two specimens plotted outside the 95\% ellipse in PC1 PC2 axes. The first three PCs of the PCA with ratios comprised $64 \%$ of the variance. When considering $\mathrm{PC} 1 \sim \mathrm{PC} 2$, all specimens plotted inside the $95 \%$ ellipse. In allometric analysis, five measurements were positively allometric, 19 were negatively allometric and three represent truly negative allometry. Many bones of the posterior and the lateral emarginations lengthen due to increasing size, while jugal and the quadratojugal decrease in width. Discussion. Image is useful in replacing caliper since there was no statistical differences. Yet, iterative imputation is more appropriate to deal with missing data in PCA. Some specimens show small differences in form and shape. Form differences were interpreted as occuring due to ontogeny, whereas shape differences are related to feeding changes during growth. 
Moreover, all outlier specimens are crushed and/or distorted, thus the form/shape differences may be partially due to taphonomy. The allometric lengthening of the parietal, quadrate, squamosal, maxilla, associated with the narrowing of jugal and quadratojugal may be related to changes in feeding habit between different stages of development. This change in shape might represent a progressive skull stretching and enlargement of posterior and lateral emargination during ontogeny, and consequently, the increment of the feeding-apparatus musculature. Smaller individuals may have fed on softer diet, whereas larger ones probably have had a harder diet, as seen in some living species of Podocnemis. We conclude that the skull variation might be related to differences in feeding habits over ontogeny in $B$. elegans. 
1 Intra-specific variation and allometry of the skull of Late Cretaceous side-necked turtle

2 Bauruemys elegans (Pleurodira, Podocnemididae) and how to deal with morphometric data

4 Thiago Fiorillo Mariani ${ }^{1}$, Pedro Seyferth R. Romano ${ }^{1}$

$5{ }^{1}$ Departamento de Biologia Animal, Universidade Federal de Viçosa, Viçosa, Minas Gerais, 6 Brazil.

7

8 Corresponding author:

9 Thiago Mariani ${ }^{1}$

10 Av. P. H. Rolfs, Anexo do Centro de Ciências Biológicas II, Third Floor, Room 305, Viçosa,

11 Minas Gerais, 36570-900, Brazil

12 Email address: tmariani.bio@gmail.com 


\section{Introduction}

\subsection{Principal Component Analysis and fossil sampling bias}

Paleontological data are intrinsically scarce (Strauss, Atanassov \& Oliveira, 2003; Hammer \& Harper, 2006), leading to incomplete data sampling. This limitation impacts several approaches in paleontological studies, especially inter-specific variation analyses. Although there are some methodologiesproposed to deal with missing entries in fossil quantitative datasets (e.g. Norell \& Wheeler, 2003; Strauss, Atanassov \& Oliveira, 2003), sometimes the study relies on an exploratory evaluation of general structure and Principal Component Analysis (PCA) is commonly used for this purpose.

PCA is a method to ordinate multivariate data. Its aim is to identify the variables that account for the majority of the variance within a multivariate matrix, by means of linear combinations of all variables, which are converted into components that are independent of each other (Strauss, Atanassov \& Oliveira, 2003; Hammer, Harper \& Ryan, 2001). Hence, PCA summarizes a large amount of the variance contained in the data (Krzanowski,1979; Hammer, Harper \& Ryan, 2001). It thus reduces a multidimensional space into fewer components which retain the majority of the variance of a given sample (Jolicoeur \& Mosimann, 1960; Peres-Neto, Jackson \& Somers, 2003), and is therefore an useful tool for exploring large, complex data sets, being largely applied to both extant and turtles (e.g. Jolicoeur \& Mosimann, 1960; Claude et al., 2004; Depecker et al., 2005, 2006; Werneburg et al., 2014; Ferreira et al., 2015). 


\subsection{Case-study}

\subsubsection{Skull variation}

The skull is one of the most variable structures in vertebrates because it concentrates several sensory organs, the brain, and the beginning of the respiratory and digestory systems, including chewing muscles (Smith, 1993). Consequently, the skull is the body partwith more phenotypes used in vertebrate cladistic analysis (Rieppel, 1993), as seen in turtles, in which most cladistic analysis rely mainly on cranial characters (e.g. Gaffney et al., 1991; de la Fuente, 2003; Gaffney et al., 2006, 2011; Joyce, 2007; Joyce \& Lyson, 2010; Sterli et al., 2010; Sterli \& de la Fuente, 2011a, b; Anquetin, 2012; Rabi et al., 2013; Romano et al., 2014; Ferreira et al., 2015; Romano, in press). Despite that, most skull materials found in paleontological record of turtles are rare and/or damaged due to the fossilization process bias, not allowing intraspecific comparisons or ontogenetic inferences on most fossil turtle species known. Some exceptions are found in Sanchéz Villagra \& Winkler (2006) and Ferreira et al. (2016), who performed interspecific comparisons among fossil turtle taxa using skull material..

\subsubsection{Bauruemys taxonomy}

Bauruemys elegans (Suárez, 1969) is a Late Cretaceous freshwater side-necked turtle found at the Pirapozinho site (Suárez, 2002), in western São Paulo state. This species was originally described as Podocnemis in three different communications by Suárez (1969a, b, c) and such recognition was based on the overall similarities of the skull and shell to this living genus, a common practice that time. Other South American Cretaceous side-necked turtles were initially identified as Podocnemis as well, such as the nomina dubia "Roxochelys" harrisi (Pacheco, 1913) and "Bauruemys" brasiliensis (Staeche, 1937) and the incertae sedis "Podocnemis" 
62 argentinensis (Cattoi \& Freiberg, 1958) (see Romano et al., 2013 for a revision on Bauru Group

63 species). Kischlat (1994) was the first to point out that all Podocnemis reported from the

64 Cretaceous were doubtful and proposed a new genus, Bauruemys, to include B. elegans and,

65 tentatively, B. brasiliensis. His conclusion was based on similarities of the plastron of both

66 species, besides the analysis of cranial features in B. elegans. More recently, Romano et al.

67 (2013) confirmed the recognition of B. brasiliensis as Bauruemys, but considering this species as nomem dubium. Kischlat (1994) and Kischlat et al. (1994) also pointed out that B. elegans could belong to Podocnemididae, but they did not test their hypothesis. Romano \& Azevedo (2006) were the first to carry out a cladistic analysis to access the phylogenetic position of Bauruemys, placing it as a stem-Podocnemididae, i.e.: the sister group of all other Podocnemididae, which was consistently confirmed by subsequent analyses with more podocnemidid species included as terminals (França \& Langer, 2006; Gaffney et al., 2011; Oliveira, 2011; Cadena, Bloch \& Jaramillo, 2012).

\subsubsection{Geological settings and taphonomic context of the Tartaruguito site}

The Pirapozinho site, long ago known as "Tartaruguito" and formally assigned as such by Romano \& Azevedo (2007) and Gaffney et al. (2011), is an Upper Cretaceous outcrop from the Presidente Prudente Formation, Bauru Basin (Geology sensu Fernandes \& Coimbra, 2000). It is located in Pirapozinho municipality, São Paulo State, Brazil (Fig. 1). The "Tartaruguito" name, which means "turtle in rock" (tartaruga, from Portuguese, turtle; ito, from Latin, rock), reflects the great amount of turtle specimens found at that place. It is comparable to other rich fossil turtle localities, such as (1) the recently discovered Middle Jurassic Qigu Formation of the

83 Turpan Basin in China (Wings et al., 2012; Rabi et al., 2013); (2) the Late Cretaceous 
85 (Lyson \& Joyce, 2009); (3) the Middle-Upper Paleocene Cerrejón Formation in Colombia

86 (Jaramillo et al., 2007; Cadena et al., 2010; Cadena, Bloch \& Jaramillo, 2012; Cadena et al.,

87 2012); and (4) the Upper Miocene Urumaco Formation ('Capa de tortugas') in Venezuela

88 (Aguilera, 2004; Sánchez-Villagra \& Aguilera, 2006; Sánchez-Villagra \& Winkler, 2006; Riff et

al., 2010; de la Fuente, Sterli \& Maniel, 2014). The two latter localities are near-shore marine coastal deposits with influence of freshwater rivers (Jaramillo et al., 2007; Gaffney et al., 2008), whereas the two former and the Tartaruguito site correspond to sediments that had been deposited in a riverine system with seasonal droughts in which turtles gathered in retreating, ephemeral water pools and died when habitat dried up completely (Soares et al., 1980; Fulfaro and Perinotto, 1996; Fernandes \& Coimbra, 2000; Henriques et al., 2002, 2005; Suárez, 2002; Murphy et al., 2003; Bertini et al., 2006; Henriques, 2006; Wings et al., 2012). The Tartaruguito is also the type-locality of the peirosauridcrocodile Pepesuchus deiseae Campos, Oliveira,

97 Figueiredo, Riff, Azevedo, Carvalho \& Kellner, 2011 (Campos et al., 2011).

The general lithology of the Tartaruguito site is composed of cyclic alternations of sandstones and mudstones deposited in a meandering fluvial system with crevasse splays (Fernandes \& Coimbra, 2000; Henriques et al., 2005; Bertini et al., 2006). Many articulated and complete fossils are found in these sequences, which indicate seasonal low energy floods (mudstones) followed by droughts (sandstones) in the region during the Late Cretaceous (Henriques et al., 2002, 2005; Henriques, 2006). Because only medium- to large-sized fossil specimens are found at the locality, it is assumed that the Tartaruguito site was a foraging area for turtles (D.

105 Henriques, pers. comm.). Thus, the fossil assemblage probably represents several episodes of 106 floods and droughts. The flood periods might have allowed foraging areas expansion for turtles 
107 and crocodiles, while during the dry seasons turtles gathered on the remnants of water pools and

108 some died when pools dried up completely (Henriques et al., 2002, 2005; Henriques, 2006).

109 That being said, we consider that all turtle specimens found at the Tartaruguito site might

110 correspond to subadults to adult ages, and it is reasonable to assume that all B. elegans

111 individuals collected in the Tartaruguito site might have belonged to a single population

112 (agreeing with Henriques et al., 2002, 2005; Henriques, 2006; Romano \& Azevedo, 2007).

113 Indeed, as suggested by Romano \& Azevedo (2007), this single population would consist on

114 different generations of turtles' corpses grouped in the same locality. One might consider that

115 size differences might be due to sexual dimorphism (R. Hirayama and S. Thomson, pers.

116 comm.), in which the females would be larger and have more posteriorly extended carapaces

117 than the males. However, sexual dimorphism on podocnemidid turtles can be assessed only on

118 shell shape and our data is based mostly on isolated skulls (see Material and Methods). As a

119 consequence, although it is possible that sexual dimorphism may affect measurements captured

120 in this study, we did not consider it, given the lack of evidence to assume such outcome. Also, to

121 our knowledge, skull shape differences related to sexual dimorphism has never been described to

122 podocnemidid turtles yet. Moreover, Romano \& Azevedo (2007) were not able to reject the

123 single population hypothesis using shell measurements (from both plastron and carapace) in a

124 morphometric approach neither to describe sexual dimorphism in the data, concluding that the

125 differences were due to ontogenetic variation. Therefore, we highlight that we are assuming the

126 population definition of Futuyma (1993), as taken on by Romano \& Azevedo (2007), that a

127 population is a conjunct of semaforonts temporally connected, i.e., a sequence of individuals

128 from different generations, and limited in a restricted space, in this case, the Tartaruguito site. By 
129

130

131

132

133

134

135

136

137

138

139

140

141

142

143

144

145

146

147

148

149

150

assuming this, we explicitly follow Hennig's (1966) semaphoront concept, on which a species is modifiable (i.e. not strictly typological) and represented by a sequence of generations.

\subsection{Objectives}

Efforts to study fossil materials may be hampered by difficulty in accessing foreign collections.

It can narrow and even preclude their studies. In addition, given the missing data problem

inherent to fossil record, the way one treatsthe missing entries in morphometric studies can affect the results and conclusions. Regarding the use of caliper or ImageJ in taking measurements, here we tested both approaches by taking linear measurements for morphometric studies based on photographs (e.g. Bailey, 2004) and also evaluated how different approaches designed to deal with missing data can impact results of exploratory statistical procedures and data interpretation by comparing two different substitution algorithms of missing entries. These procedures are exemplified using a real paleontological data set and with paleobiological inferences.

Considering the case-study, we explored the variation in skulls among individuals of Bauruemys elgans from different ages and generations. and described the differences in skull morphology along the ontogeny of the species and discuss the probable consequences of such variation to the diet preferences changes along the growth.

\section{Material and Methods}

\subsection{Sample and characters}

Twenty-one skulls of Bauruemys elegans were examined in this study, including the type series plus nineteen topotypes: AMNH-7888, LPRP0200, LPRP0369, LPRP0370, MCT 1492-R (holotype), MCT 1753-R (paratype), MCZ 4123, MN 4322-V, MN 4324-V, MN 6750-V, MN 6783-V, MN 6786-V, MN 6787-V, MN 6808-V, MN 7017-V, MN 7071-V, MZSP-PV29, 
151 MZSP-PV30, MZSP-PV32, MZSP-PV34, and MZSP-PV35. We established 39 landmarks (Fig.

152 2) that decompose the overall shape of the skull in order to take measurements between two

153 landmarks. Since most of the specimens have deformation and breakage, we could not perform a

154 geometric morphometric analysis using the landmarks because the taphonomical bias would

155 incorporate error to the analysis of form and shape. Thus, we used the landmarks to set up 29

156 traditional morphometric characters that correspond to a linear measurement between two

157 landmarks (all characters are described in table 1). Also, the use of landmarks to set up the

158 measurements is useful to maintain the same anatomic references for all characters in each

159 specimen, since the landmarks enable a better description of morphological variation and

160 establishment of linear measurements, as performed by Romano \& Azevedo (2007) with shell

161 morphometric characters. All measurements were taken on the same side of the skull (right side)

162 unless the characters could not be measured due to deformation or breakage. We are aware that

163 deeper structures (z-axis) can influence the straight line between two landmarks in 2D images

164 and used ImageJ version 1.47 (Rasband, 1997) to take the measurements after comparing its

165 accuracy with the caliper (Mariani \& Romano, 2014). This procedure was necessary because we

166 obtained photos of skulls in dorsal, ventral, and lateral views housed in foreign collections and

167 did not perform the described measurements (see table 1) using caliper in such specimens

168 because they were analyzed prior to this study. The error test between measurements taken using

169 caliper and ImageJ using part of the sample are described below. We followed the bone

170 nomenclature of Parsons \& Williams (1961) and extended by Gaffney $(1972,1979)$ (see all

171 abbreviations after Conclusion topic).

172 2.2. Statistical analyses

173 2.2.1. Preliminary analysis: Caliper vs. ImageJ 
174 Before carrying out others statistical analyses, we compared the same characters data set (Data

175 S1) of a sub-sample by using two different approaches (= treatments): measurements taken using

176 caliper and measurements taken using photographs via ImageJ. This comparison was necessary

177 in order to evaluate whether or not the two measurements methods are significantly different.

178 Then, we performed an One-way Analysis of Variance (ANOVA) comparing the 29

179 measurements in 12 specimens (LPRP0200, LPRP0369, LPRP0370, MN4322-V MN4324-V, 180 MN6750-V, MN6783-V, MN6786-V, MN6787-V, MN6808-V, MN7017-V, and MN7071-V).

181 Two groups of variables were established: measurements taken directly from specimens using 182 caliper (preliminary data set 1) and the same characters taken from photographs of the same specimens using ImageJ (preliminary data set 2). All characters taken using photographs/ImageJ that did not show significant differences to their correspondents taken by caliper were used on the subsequent statistical analyses of form and shape differences among the sample of Bauruemys elegans. By doing that, the sample was increased without including error and incomparable characters (i.e.: by using different measurement techniques).

We found most of the measurements do not differ statistically $(p>0.05)$ between the two treatments (caliper and ImageJ; table 1). However, one measurement, length of maxilla (LMX), had statistical difference $(p=0.017)$ between the treatments, because the maxilla is a curved structure and thus the landmarksare in different positions (LM 24 is deeper and farther from the camera in relation to LM11) in relation to the plane the picture was taken. Given that no statistical differences were found in almost all characters, Image J could be an economic and

194 time-saving tool for morphometric analyses from photographs (2D), and could be applied by 195 scientists at distant institutions. 
196 The study in situ of the material is preferable, although pictures are an economic alternative in

197 where cases one is not able to handle the material. We must aware that one have to choose one of

198 the two treatments to construct a morphometric matrix, otherwise it will be composed of values

199 obtained by two diffent methods.

\section{2.2.2. Univariate, multivariate and allometric analyses}

201 Three analyses using the complete sample were carried out: (1) a descriptive statistics (mean,

202 standard deviation, median, variance, maximum and minimum values) of all characters (Data

203 S2), (2) an allometric analysis of length and width characters correlating them to total length and

204 width measurements (Data S3), and (3) a multivariate non-parametric exploratory statistics via

205 Principal Component Analysis (PCA). The latter was divided into two different PCAs: (3.1)

206 using 27 characters from the raw data matrix (total length and width characters were excluded in

207 this analysis; Data S4 - because PCA is sensitive to wide-scale variations in the original

208 measurements), and (3.2) using 27 charactersthat correspond to the proportions of each character

209 from the raw data (i.e. original measurements) represented by its length or width characters

210 divided by each individual total length or width (e.g. the length of MCZ4312 postorbital divided

211 by the total length of the skull of this specimen; see complete data in Data S5). All statistical

212 analyses were performed using the software PAST version 3.05 (Hammer et al., 2001).

213 In the allometric analysis (analysis 2, Data S3), all characters were previously log-transformed

214 and a linear regression was carried out separately for length and width characters, using the least

215 square fitting approach for residuals. We established the allometries by considering the

216 regression's slope, i.e. the coefficient a, as following: positive allometry (a>1), negative

217 allometry $(1>a>0)$, enantiometry $(a<0)$, and isometry $(a=1)$. 
218 In the first PCA approach (3.1) we excluded total length and width characters because of their

219 high influence on the PCA result, since higher values compose the majority of the summarized

220 variance in PC's (Mingoti, 2013), and because of the redundancybetween these measurements

221 and the others. We also assessed differences by applying two different substitution algorithms for

222 missing data in PAST, using the default "mean value imputation" option (i.e. missing data are

223 replaced by the column average), and the alternative "iterative imputation" option, which

224 computes a regression upon an initial PCA until it converges to missing data estimations,

225 replacing missing data by such estimations (Ilin \& Raiko, 2010). The latter is recommended and,

226 after comparing both results, we selected it (see supplemental material 3 to visualize PCA results

227 computed using PAST's default option approach). The second PCA (3.2) was conducted to

228 remove the effect of size (=growth) and perform an exploratory analysis of the shape alone. Six

229 specimens were removed from this analysis because they were broken and the total length or

230 width measures were not measurable.

231 The univariate analysis was made in order to quantify and describe the variation of the characters

232 set in Bauruemys elegans skull, using the assumption thatthe sample is representative of a single

233 population. The linear regression analyses allowed us to make inferences about osteological

234 shape change related to size change, i.e., related to growth, by assuming that bigger specimens

235 are older than smaller ones. This approach is, therefore, a study of allometry (sensu Huxley \&

236 Teissier, 1936; Huxley, 1950; Gould, 1966; Gould, 1979; Somers, 1989; Futuyma, 1993) and the

237 assumption of correlation between size and aging is based on continuous growth to be common

238 on extant turtles (Klinger \& Musick, 1995; Shine \& Iverson, 1995; Congdon et al., 2003). Since

239 the use of a parametric statistic was infeasible due to the nature of the sample (i.e.: a small

240 datasetthat do not show homoscedasticity and normality), the PCAs were used to search for a 
241 structure of the data that matches to the pattern found by Romano \& Azevedo (2007) using shell

242 characters (i.e. all individuals plotted inside the 95\% confidence ellipse). If the pattern observed

243 is similar to previous morphometric and taphonomic inferences, then the variation is not enough

244 to assume that the sample represents different populations of Bauruemys elegans or a different

245 species (see section 4.1.2). In other words, since a parametric test is not feasible with statistical

246 confidence, the lack of structure in the PC plots were herein interpreted as a fail to the attempt of

247 falsifying the single population hypothesis. All principal components were, therefore, analyzed

248 but we present only those with higher variance.

\section{3. Results}

\subsection{Descriptive Analysis}

251 The results of the descriptive statistics are summarized in table 2. As expected, values of total

252 length and width (TLS and WLS) were the most variable among all measurements, because the

253 variation scale in these characters is greater than in others measurements. Characters of the bones

254 forming the upper temporal fossa (i.e. PA, QJ, SQ, QU and OP) had great variation, with the

255 parietal being the most variable in length $(\mathrm{SD}=6.45)$ and the least variable in width $(\mathrm{SD}=2.94)$,

256 whereas quadratojugal obtained the smallest variation in length $(\mathrm{SD}=2.38)$ and the greatest in

257 width $(\mathrm{SD}=4.03)$. Among the characters of the bones forming the lower temporal fossa (i.e. JU,

258 MX, PO, PT and PAL), the variation in length was in general greater than in width. Postorbital

259 and maxilla had almost the same variation in length ( $\mathrm{SD}=4.12$ and $\mathrm{SD}=4.11$, respectively); WPO

260 had the smallest variation within the group of bones forming the lower temporal fossa

$261(\mathrm{SD}=1.83)$; and the stretch of the maxilla had the greatest variation $(\mathrm{SD}=7.63)$ of all characters

262 measured. Characters of the other bones had smaller values than the aforementioned bones, with 
263 the exception of WPO which was smaller than LFR (SD=2.08), LVO (SD=1.95), LBO

$264(\mathrm{SD}=2.12), \mathrm{WFR}(\mathrm{SD}=1.88)$ and WBS $(\mathrm{SD}=2.19)$.

\section{3.2. Allometric Analysis}

266 Among all comprised measurements, three were truly negatively allometric (LPF, WJU and

267 WQJ); five were positively allometric (LPAL, LPT, LPO, WPF and WPO); and the others were

268 negatively allometric. It is also worth to note that two were not isometric [WPF $(a=1,0074$;

269 $p=0.0009)$ and WOP $(\mathrm{a}=0.98159 ; p=0.007)]$, although presented angular coefficient very close to

270 1. All regressions are shown in figures 3, 4 and 5.

\subsection{Principal Component Analysis (PCA)}

\subsubsection{Raw data}

\subsubsection{Replacing missing data with mean values}

274

275

276

277

278

By using the "mean value imputation" approach, a total of $70.32 \%$ of the variance was comprised by the first three principal components ( $\mathrm{PC} 1=42.15 \% ; \mathrm{PC} 2=16.82 \% ; \mathrm{PC} 3=11.35 \%)$, so that the others were less significant for the analysis by following the broken stick model, and are not presented. We interpreted that PC1 variation is due to size variation because an approach using all characters has shown a similar plot (see Fig. 6A). PC2 and PC3 seems to represent shape differences between individuals. In all PC individual projections (Fig. 6A and 6B) most of specimens were included inside the 95\% confidence ellipse. Two exceptions are MCZ4123 and MN7071-V, which have not been included in the ellipse when PC1 vs. PC2 were considered (Fig. 6A); also the former was outside the ellipse in PC2 vs. PC3 scatter plot (Fig. 6B), 
283 indicating shape differences of these specimens. However, both specimens have suffered

284 different degrees of crushing due to taphonomic bias and that is likely the reason for this result.

285 In PC1' loadings (Table 3), only two characters were negatively related (LPF and WJU); SMX,

286 LPA and LPO loadings were the highest related ( $\mathrm{L}=0.69 ; \mathrm{L}=0.27 ; \mathrm{L}=0.36$, respectively); and the

287 rest of characters obtained intermediate values [e.g. LPT ( $\mathrm{L}=0.17), \mathrm{LMX}(\mathrm{L}=0.18)$, WOP

$288(\mathrm{~L}=0.21)]$. PC2 has shown a high relation with character LPA $(\mathrm{L}=0.77)$, showing possible

289 changes in shape in this region, and a negative loading for $\mathrm{SMX}(\mathrm{L}=-0.38)$, whereas the others

290 had no significant scores. The last considered principal component (=PC3), showed high

291 correlations with bones in both lateral and posterior emarginations of the skull [LMX ( $\mathrm{L}=0.68)$,

292 WMX $(\mathrm{L}=0.25)$, LJU $(\mathrm{L}=0.30)$, WQJ $(\mathrm{L}=0.29)$ and $\mathrm{LQU}(\mathrm{L}=0.32)]$ and, as the results in PC2,

293 allows inferences in shape changes of these regions.

\section{3.3.1.2. Replacing missing data with regression estimation}

295 The alternative missing data approach (i.e. "iterative imputation"; Fig. 6C) generated two

296 principal components which comprised $88.96 \%$ of the total variance $(\mathrm{PC} 1=53.01 \%$;

297

$\mathrm{PC} 2=35.95 \%$ ). In contrast with the previous approach, PC1 was interpreted as representing shape

and PC2 reflected size variations. In addition, all specimens were included inside the $95 \%$ ellipse

299

in PC1vs.PC2 scatter plot. The specimen MN7017-V, interestingly, was excluded from the

ellipse when considering PC2 vs. PC3, but the percentage of variance represented by PC3 is too

301

low $(\mathrm{PC} 3=3.28 \%)$ to assume any difference from the others individuals. We agree with Ilin \&

Raiko (2010) and prefer to choose the iterative imputation approach for dealing with missing entries (see discussion on session 4.1). Then, discussions concerning the form variation in our data are related to PCA analysis using iterative imputation. 
305 In PC1 loadings (Table 3), LPA, WPA and LSQ were the highest positively related characters $306(\mathrm{~L}=0.89 ; \mathrm{L}=0.22 ; \mathrm{L}=0.16$, respectively), whereas $\mathrm{LMX}, \mathrm{LJU}, \mathrm{LQJ}, \mathrm{WQJ}$ and LQU were the 307 highest negatively related characters $(\mathrm{L}=-0.18 ; \mathrm{L}=-0.14 ; \mathrm{L}=-0.16 ; \mathrm{L}=-0.11 ; \mathrm{L}=-0.11 ; \mathrm{L}=$ 308 0.13, respectively). Only two characters were negative for PC2 (LPF and WJU), whereas the rest 309 of the coefficients were positive. Among them, SMX was the highest (L=0.59); WPAL, WBS,

310 LBO, LJU, LQU, LPO and WOP obtained intermediate scores $(\mathrm{L}=0.23 ; \mathrm{L}=0.19 ; \mathrm{L}=0.20$;

$311 \mathrm{~L}=0.19 ; \mathrm{L}=0.21 ; \mathrm{L}=0.29 ; \mathrm{L}=0.30$, respectively); the others were less related [e.g. LPA ( $\mathrm{L}=0.04)$,

312 LPT $(\mathrm{L}=0.13)$ and WPO $(\mathrm{L}=0.10)]$. In general, the values indicate that in $B$. elegans most 313 changes occur in bones of both lateral and temporal emargination.

\section{3.3.2. Shape characters (proportions)}

\subsubsection{Replacing missing data with mean values}

316

317

318

319

320

321

322

323

324

325

When applying "mean value imputation", $53.99 \%$ of the variance were comprised by the first two principal components $(\mathrm{PC} 1=35.29 \% ; \mathrm{PC} 2=18.70 \%)$, both corresponding to shape, as all units of measurements were removed through the division of characters before carrying out the analysis. All specimens were comprised into the 95\% confidence ellipse (Fig. 7A).

The first PC was positively related to the loadings values of LPA/TLS ( $\mathrm{L}=0.28)$, LMX/TLS (L=0.38), LQU/TLS ( $\mathrm{L}=0.27), \mathrm{WPA} / \mathrm{TWS}(\mathrm{L}=0.23), \mathrm{SMX} / \mathrm{TWS}(\mathrm{L}=0.38), \mathrm{WMX} / \mathrm{WTS}$ $(\mathrm{L}=0.35), \mathrm{WQJ} / \mathrm{TWS}(\mathrm{L}=0.48)$; the most negative values were $\mathrm{LPO} / \mathrm{TLS}(\mathrm{L}=-0.16)$ and WOP/TWS $(\mathrm{L}=-0.13)$. The second PC was positively related to LPA/TLS $(\mathrm{L}=0.66), \mathrm{WPA} / \mathrm{TWS}$ $(\mathrm{L}=0.32) \mathrm{WOP} / \mathrm{TWS}(\mathrm{L}=0.27)$, and negatively to $\mathrm{LMX} / \mathrm{TLS}(\mathrm{L}=-0.50)$ (see Table 4 for all loading values). It is interesting to note that most of highly-related proportions were in reference 
326 to bones associated either with feeding apparatus (squamosal, parietal, quadratojugal and jugal)

327 or catching food and trituration surface (maxilla).

\section{3.3.2.2. Replacing missing data with regression estimation}

329 The "iterative imputation" substitution model of missing data explained $77.35 \%$ of the variance 330 comprised by two principal components $(\mathrm{PC} 1=45.49 \%$; $\mathrm{PC} 2=31.86)$, both representing shape.

331 All specimens were included in the confidence ellipse (Fig. 7B), thus shape differences do not 332 indicate possible different populations or species.

333 PC1 was highly related to LMX/TLS ( $\mathrm{L}=0.48)$, LJU/TLS ( $\mathrm{L}=0.16), \mathrm{LQJ} / \mathrm{TLS}(\mathrm{L}=0.21)$,

$334 \mathrm{LQU} / \mathrm{TLS}(\mathrm{L}=0.28), \mathrm{LSQ} / \mathrm{TLS}(\mathrm{L}=0.20), \mathrm{SMX} / \mathrm{TWS}(\mathrm{L}=0.33), \mathrm{WMX} / \mathrm{TWS}(\mathrm{L}=0.30)$,

335 WJU/TWS $(\mathrm{L}=0.26)$ and WQJ/TWS $(\mathrm{L}=0.41)$, which represent the highest values, as well as

336 bones constituting both lateral and posterior emargination. Conversely, PC2 was mostly

337 represented by LPA/TLS ( $\mathrm{L}=0.67)$, LSQ/TLS $(\mathrm{L}=0.34)$ and WPA/TWS (L=0.33) (see Table 4).

338 These loadings represent shape changes in regions of the skull that are associated with muscles'

339 attachments as well as trituration surfaces (see below).

\section{4. Discussion}

\section{4.1. The single population hypothesis}

342 In this section, we discuss the single population hypothesis considering two fronts, one underlied

343 on the taphonomy of the Tartaruguito locality, and another on the possibility of the skull

344 variation represent one or more specimens of species Roxochelys wanderleyi in the sample, a 345 shell-only species also found at the site. 
347 The depositional environment at the Pirapozinho site is well-known from previous studies, which

348 point out to seasonal floods in which turtles might have gathered in water bodies for foraging,

349 followed by droughts that caused their death (Soares et al., 1980; Fulfaro and Perinotto, 1996;

350 Fernandes \& Coimbra, 2000; Henriques et al., 2002, 2005; Suárez, 2002; Bertini et al., 2006;

351 Henriques, 2006). This is, consequently, a case of several seasonal non-selective death events,

352 with individuals representing semaphoronts connected temporally (between generations), thus

353 comprising a single population (agreeing with Futuyma, 1993 population definition and used by

354 Romano \& Azevedo, 2007). We failed to disprove the null hypothesis that all individuals belong

355 to a same population of Bauruemys elegans, agreeing with Romano \& Azevedo (2007)

356 conclusion using post-cranium data.

357

\subsubsection{Taxonomic considerations on the sample}

Many skulls sampled show taphonomic effects, such as cracks and crushing (Fig. 8). For instance, MN7071-V is notably the largest specimen of the sample and is represented in the uppermost positive side of the size-related PC2 axis (Fig. 6C). Although it is indeed a big specimen, it was clearly a taphonomic effect (crushing) that caused it to be larger than it really was (Fig. 8A). On the other hand, Bertini et al. (2006) indicated that turtle bodies have suffered little transportation or crushing in Tartaruguito site. We agree with this taphonomical interpretation of the site, as most specimens do not show huge breaks (Fig. 8B and 8C) that could cause misinterpretation of the morphometric results (the case of MN7071-V is an exception in our sample in this respect).

Another aspect is the presence of polymorphism in B. elegans. Romano (2008) presented an unusual carapace for the specimen MN7017-V, as having a seventh neural bone, differing from 
369 the diagnostic number of six neurals for this species, and with the diagnostic four-squared second

370 neural bone not contacting first costals (Suarez, 1969; Kischlat, 1994; Gaffney et al., 2011). The

371 morphometric analysis performed by Romano (2008) did not reveal significant statistical

372 differences between MN 7017-V and other B. elegans specimens. We have included the

373 MN7017-V skull in our analysis, and there was no variation to state anything apart from

374 Romano's (2008) conclusion that it is probably a polymorphic B. elegans specimen (Fig. 6C).

375 Still, we reevaluated this skull and found the diagnosticcharacters for B. elegans. Therefore, all

376 skulls included in our study belong to the same species (i.e. B. elegans).

377 Among the five valid fossil turtle species found throughout the Bauru Basin, only two have been

378 collected at the Pirapozinho site so far (Romano et al., 2013). The first is B. elegans, which is

379 recognized by both skull and shell materials; the second is Roxochelys wanderleyi Price, 1953,

380 based only on shell material (de Broin, 1991; Oliveira \& Romano, 2007; Romano \& Azevedo,

381 2007; Gaffney et al., 2011; Romano et al., 2013). So far, none R. wanderleyi with skull-shell

382 associated body parts were collected, and thus we cannot claim that the skulls found at

383 Tartaruguito site belong to this species until a skull-shell $R$. wanderleyi specimen be found, since

384 all analyzed skulls can be safely identified as belonging to B. elegans.

385

386

387

388

389

390

\subsection{Ontogenetic changes in B. elegans skull}

Once we have assessed that all specimens belong to the same species and are likely from the same population, we are able to discuss the skull variation in the sample assuming as due to inter-populational variety. For the sake of organization, we divided the discussion into two parts, based on the anatomical regions of the turtle skull: upper temporal fossa and lower temporal fossa, following Schumacher (1973), Gaffney (1979) and Gaffney et al. (2006). We have chosen 
391 this organization because the bones we found most associated with the principal components in

392 the two PCA analyses constitute these two regions and are generally involved in aspects of the

393 feeding mechanisms of turtles, either as muscles attachments or forming triturating surfaces.

\section{4.2.1. Bones of the upper temporal fossa and skull roofing}

395 The temporal emargination of podocnemidid turtles is formed by the dorsal, horizontal plate of

396 the parietal, the quadratojugal and the squamosal, with no contribution of the postorbital

397 (Gaffney, 1979; Gaffney et al., 2011). This region (and bones) is associated with the origin of the 398 adductor muscle fibers (m. adductor complex; Fig. 9A and 9B) (Schumacher, 1973; Werneburg, 399 2011; Werneburg, 2012; Jones et al., 2012; Werneburg, 2013), which run through cartilago 400 transiliens of the processus trochlearis pterygoidei of the pterygoid and insert at the coronoid 401 process of the lower jaw (Schumacher, 1973; Gaffney, 1975; Gaffney, 1979; Lemell et al., 2000;

402 Werneburg, 2011). These muscles promote the closure of the mouth, thus it is reasonable to 403 associate the attachment surface to bite force and the latter to the prey hardness. Yet, on the 404 ventral flange of the squamosal originates the m. depressor mandibulae (Schumacher, 1973; 405 Gaffney et al., 2006; Werneburg, 2011; Fig. 9B), which causes the abduction (=opening) of the 406 mandible.

407 The variation in this area of the skull in turtles was a matter of some studies (e.g. Dalrymple, 408 1977; Claude et al., 2004; Pfaller et al., 2011), which indicated allometric ontogenetic growth 409 patterns of the bones in these regions. These authors were able to identify a high correlation with 410 the increasing of muscle mass and shift in feeding features (Dalrymple, 1977; Pfaller et al., 2010;

411 Pfaller et al., 2011). Moreover, there are changes in skull shape associated to the aquatic 412 environment and foraging strategies, as suggested for emydid and testudinoid turtles by Claude 
413 et al. (2004). Although these studies focused on hide-necked turtles, the same morphoecological

414 patterns can be applied to side-necked turtles, since there are habitat occupation similarities

415 between side-necked and hide-necked turtles with implications to the skull morphology due to

416 morphofunctional constraints (Schumacher, 1973; Lemell et al., 2000), besides the adaptive

417 selection regarding fresh water feeding strategies (see Lauder \& Prendergast, 1992, Aerts et al.,

4182001 and Van Damme \& Aerts, 2001 for feeding strategies in freshwater turtles).

419 The high variance and positive allometric growth of the parietal (LPA: $a=0.38$; WPA: $a=0.32$ ),

420 quadratojugal (LQJ: $a=0.16$; WQJ: $a=-0.06$ ) and squamosal (LSQ: $a=0.30$ ) lead to an increase in

421 temporal emargination and, consequently, a greater area for attachment of the m. adductor

422 mandibulae externus. The consequence of this would be the generation of large forces and high

423 velocities during the fast closing phase of an aquatic feeder, as seen in Pelusios castaneus

424 (Lemell et al., 2000), and even a more powerful bite for crushing harder prey, as seen in

425 Sternotherus minor (Pfaller et al., 2011). In addition, the lenghten of the squamosal would allow

426 a greater insertion area of the $\mathrm{m}$. depressor mandibulae and muscles of the hyobranchial

427 apparatus (e.g. m. constrictor colli) (Schumacher, 1973; Gaffney, 1979; Claude et al., 2004;

428 Gaffney et al., 2011; Werneburg, 2011). The $m$. depressor mandibulae is useful for an increased

429 gape opening speed and the hyobranchial apparatus musculature is involved in backwards water

430 flow generation by the lowering of the hyoid apparatus, two characteristics well reported for

431 other pleurodire turtles as Chelodina longicollis, Chelus fimbriatus and Pelusios castaneus

432 (e.g.Van Damme \& Aerts, 1997; Aerts et al., 2001; Lemell et al., 2000; Lemell et al., 2002).

433 Moreover, Claude et al. (2004) demonstrated that aquatic turtles with suction feeding mode

434 possess longer skulls than terrestrial turtles, the squamosal being most prominent bone involved 
435 in this elongation and functionally related to the style of prey capture (= suction) as a support for 436 mandible and hyoid muscles.

437 Also, Gaffney et al. (2011), in a comparison with other podocnemidid turtles, indicated $B$.

438 elegans as having a "skull relatively wide and flat" (p. 12), which could be observed by the

439 increasing of some bones, specially the postorbital (Figs. 3G and 4H), parietal (Fig. 3A and 3J),

440 quadratojugal (Figs.3I and 4F) and jugal (Figs. 3C and 5B). Comparing the postorbital allometry

441 (better discussed below) with those of the bones in contact with it in the skull roof (frontal,

442 parietal, jugal and quadratojugal; Gaffney et al., 2011), we observe an influence of the positive

443 growth of the former into the others, leading to flattening and widening of the skull.

444 In a study assessing the bite performance in turtles, Herrel et al. (2002) suggested that a higher

445 skull is efficient in promoting stronger bite forces, specially in species which feed on hard prey,

446 but they also pointed out that additions in bite forces may be achieved by "getting longer and

447 larger" skull with no increasing in skull height. Thus, in addition to provide gains in muscle

448 attachment area, by the growing of parietal, quadratojugal and squamosal, leading to a longer

449 skull, a stronger bite and possibly a change in diet along the ontogeny. Also, the allometric

450 growths of most of skull bones, particularly the positive allometry of the postorbital, suggests a

451 more roofed skull in $B$. elegans bigger adults. Given the allometric patterns aforementioned, $B$.

452 elegans may have had a wide and flat but long skull, which would have compensated the loss of

453 muscle volume and attachment area caused by widening and flattening the skull (Herrel et al.,

454 2002). Correlations between a more emarginated skull and increases in the volume of the

455 adductor muscles were also explored in a cranial evolutionary framework of stem-turtles by

456 Sterli and de la Fuente (2010). 
457 At last, Gaffney et al. $(2006,2011)$ scored a character based upon the contact between

458 quadratojugal and parietal bones (char. 13 of Gaffney et al., 2006; char. 5 of Gaffney et al.,

459 2011). They also state that this contact is present in Hamadachelys + Podocnemididae clade,

460 with a large quadratojugal (state 1), in contrast to most of other Pelomedusoides (state 0: contact

461 absent, as seen in Pelomedusidae, Araripemydidae and many bothremydids (e.g.

462 Kurmademydini, Cearachelyini and Bothremydini); state 2: contact present with small

463 quadratojugal in some Taphrosphyini, Bothremydidae). Indeed B. elegans possess a large

464 quadratojugal, which means that the reduction of the postorbital evolved after Bauruemys node

465 of divergence, as confirmed in performed cladistic analyses. However, we found a greater

466 increasing (positive allometry) of the two measurements of the postorbital and this might have

467 influenced the growth of parietal and quadratojugal, as well as the jugal (see below), so that the

468 state 1 seen in B. elegans is possibly a consequence of allometric changes. This is easily seen

469 when comparing the enatiometry of the width of the quadratojugal (WQJ: $\mathrm{a}=-0.06$ ) and the slight

470 increasing in the length of this bone (LQJ: $\mathrm{a}=0.16)$ with the postorbital measurements. It also

471 could have influenced the growth of the parietal, but to a lesser extent, as seen in the allometries

472 of this bone (LPA: $\mathrm{a}=0.38$; WPA: $\mathrm{a}=0.32)$.

473 When comparing the stem-Podocnemidinura species (i.e. Brasilemys, Hamadachelys) and stem-

474 Podocnemididae (e.g. Bauruemys, Peiropemys, Pricemys and Lapparentemys), with the

475 Podocnemidodda (i.e. Podocnemidand + Erymnochelydand) (Gaffney et al., 2011; Fig. 8), it is

476 clear that an increasing in the parietal-quadratojugal contact has occurred along the

477 podocnemidid lineage, and consequently led to a more roofed and less emarginated skull. We

478 suggest that in B. elegans the small contact is due to the positive growth of the postorbital

479 resulting in a more emarginated skull than other podocnemidids, as described by Gaffney et al. 
480 (2011). Yet, within Podocnemidoddathis bone suffered the opposite effect (i.e. small growth),

481 showing variations in size and even being absent in some species (e.g. Podocnemis

482 sextuberculata; Ruckes, 1937; Gaffney, 1979; Gaffney et al., 2011), though the emargination is

483 still great. On the other hand, in Erymnochelydand the postorbitals are large but the

484 quadratojugal and parietal are large as well, leading to a greater contact between these bones and

485 a well-roofed but less emarginated skull, being a reversion in Bairdemys venezuelensis and $B$.

486 sanchezi within Erymnochelydand (Gaffney et al., 2011). Therefore, the increase or decrease in

487 the temporal emargination within Podocnemididae could be due to variation of allometric

488 patterns in bones that form the skull roof, particularly the postorbital, quadratojugal, and parietal,

489 among different lineages. Given that observation, we speculate that characters related to the form

490 of the aforementioned bones (postorbital, squamosal, and parietal) are potencially more

491 susceptible to homoplasy.

\subsubsection{Bones of the lower temporal fossa}

493

494

495

496

497

498

499

500

501

502

The lower adductor chamber in Pelomedusoides is formed externally and laterally by the jugal and quadratojugal, with the addition of the maxilla in some cases (e.g.: Podocnemis spp. and Bairdemys sanchezi). The well developed cheek emargination, found in most but not all podocnemidid turtles (the exceptions are allErymnochelydand, but Bairdemys spp., Cordichelys antiqua and Latentemys plowdeni), is also part of the adductor chamber (Gaffney, 1979; Gaffney et al., 2006; Gaffney et al., 2011). Internally and medially, the postorbital, the jugal, and the pterygoid compose the septum orbitotemporale, partially separating the fossa orbitalis from the fossa temporalis; along with the palatine, they aid to support the processus trochlearis pterygoidei of the pterygoid (Gaffney, 1975; Gaffney 1979; Gaffney et al., 2006). There is a passage medially to the process of the pterygoid and the septum orbitotemporale, running from 
503 the fossa orbitalis to the fossa temporalis, the sulcus palatinopterygoideus. The palatine and

504 pterygoid form the floor of its passage, whereas the parietal, postorbital and frontal limit its

505 upper portion. In this region, the m. adductor mandibulae fibers run through the processus

506 trochlaris pterygoidei, and the $m$. adductor mandibulae internus (i.e. $m$. pterygoideus and pars

507 pseudotemporalis; Fig. 9B) mostly originates throughout the pterygoid and parietal bones

508 (Schumacher, 1973; Lemell et al., 2000; Lemell et al., 2002; Werneburg, 2011). The m. adductor

509 mandibulae internus fibers are involved in the jaw-closure system by generating counter forces

510 (protraction) to the m. adductor mandibulae externus (retraction) (Schumacher, 1973; Lemell et

511 al., 2000; Lemell et al., 2002; Fig. 9C and 9D).

512 Variation of the upper temporal fossa has been studied in different turtles, such as various

513 trionychids (Dalrymple, 1977) and Chelydra serpentina (Herrel et al., 2002). However, few

514 studies report the variation of the lower adductor chamber, although both the upper and lower

515 temporal fossa are anatomically and functionally coupled (Schumacher, 1973). Dalrymple (1977)

516 identified a positive allometry in the width of the "temporal passageway" in trionychids. This

517 area is related to the cryptodire pulley system (i.e. a processus trochlearis formed by the

518 quadrate and opisthotic) and is analogous to the pleurodire pterygoid process, and thus can be

519 comparable functionally (Gaffney, 1979). Herrel et al. (2002) concluded that the increase of the

520 bite force in turtles is due to either the increased height of the skull, leading to a more open angle

521 of the processus trochlearis in relation to skull longitudinal axis, or to enlargement (in width and

522 length) of the skull, because it allows more area for muscle attachment and volume. We observed

523 the same pattern of growth change in B. elegans, as evidenced by the positive allometry of the

524 parietal, postorbital, palatine and pterygoid bones. Other features were observed by Dalrymple

525 (1977) in trionychids (e.g. height and width of the supraoccipital crest, lengthening of the 
526 squamosal crest and a development of a horizontal crest in the parietal) and were correlated to 527 changes in skull shape with a shift in feeding habits, from softer to harder preys as individuals 528 age. Again, this seems to be the case in B. elegans, as evidenced by the positive allometry of the 529 squamosal and parietal bones.

530 The bones that mainly compose the skull rostrolaterally and the lateral emargination revealed a 531 correlated allometric shape shift. Even so, jugal and maxilla showed small allometric variation 532 (Figs. 4B, 4C, 6A, and 6B). The reduction of the jugal (WJU: $\mathrm{a}=-0.23$ ) and quadratojugal (WQJ: $533 \mathrm{a}=-0.06$ ) along with the small growth of the maxilla (WMX: $\mathrm{a}=0.19)$ demonstrate a decrease in

534 height at the anterior portion of the skull. Because of the contact between jugal and quadratojugal 535 with the postorbital (and its increase; see previous topic), we suggest that the latter would 536 possibly has affected the growth of the former bones. Moreover, the strong development of the 537 postorbital would ultimately affect the width of the maxilla, which in turn would also affect the 538 jugal. In contrast, the lengthen of this bone would be less affected (LMX: a=0.39). In addition, 539 there is a considerable increment in the stretch of maxilla (SMX: $\mathrm{a}=0.70)($ Fig. $3 \mathrm{H})$ leading to a 540 broader rostrum. Yet, this could allow a greater area for crushing, as observed by Kischlat (1994)

541 for B. elegans, but also related to ontogenetic growth (pers. obs.). All these allometric changes

542 indicate that B. elegans owns a more flattened and wider skull (Gaffney et al., 2011), which

543 could have allowed greater bite forces generation (Herrel et al., 2002).

544 There are other morphological implications in which the lower adductor chamber bones are 545 involved and that are worth discussing. As previously pointed out, three bones compose the 546 septum orbitotemporale: pterygoid, jugal, and postorbital (Gaffney, 1979; Gaffney et al., 2006).

547 Together with the palatine, these three bones provide support for the processus trochlearis 548 pterygoidei, whereupon runs the tendon that connect the m. adductor externus complex into the 
549 lower jaw (Schumacher, 1973; Gaffney, 1975; Gaffney 1979; Lemell et al., 2000; Gaffney et al.,

550 2006; Werneburg, 2011). Nearby the process, many muscle fibers originate or cross towards

551 their insertions points (Schumacher, 1973; Werneburg, 2011). The temporal emargination at the

552 upper adductor chamber becomes more emarginted during growth. As a consequence, the

553 attachment area for $m$. adductor mandibulae externus increase during aging, potentially

554 generating stronger bite forces. The consequence of this temporal emargination indentation is

555 that the trochlear process would must become more robust to support higher forces. We interpret

556 that the positive allometries of pterygoid (LPT a=1.37), postorbital (LPO a=1.25 and WPO

$557 \mathrm{a}=1.36$ ), and palatine (LPAL a=1.11) could be a response to this robustness of the trochlerar

558 process during growth. In other words, they would act together by giving more resistance to the

559 area in which the high forces created by the m. adductor mandibulae externus are applied.

560 Gaffney (1979) suggested this robustness occurs because muscle volume increase and,

561 consequently, higher bite forces, so these three bones would reinforce the septum

562 orbitotemporale in order to support and do not break when muscles are contracted. In addition to

563 such reinforcement, the growth of palatine could be associated with a larger area for crushing

564 preys such as mollusks and crustaceans, as pointed out by Kischlat (1994).

565 The m. adductor mandibulae internus and m. adductor mandibulae posterior (Fig. 9B), which

566 originate at the quadrate, prootic, pterygoid, palatine, postorbital and the descending process of

567 the parietal (Schumacher, 1973; Werneburg, 2011), are important during the jaw-closure phase.

568 The importance of these muscles has been debated for early tetrapods with flat skull and aquatic

569 lifestyle (e.g. Temnospondyli and Lepospondyli; Frazzetta, 1968), in which the internal muscle

570 might have assumed the main function of closing the jaw (Werneburg, 2012). This also occurs in

571 turtles with flat skulls and with poorly developed crista supraoccipitalis (e.g. Chelidae; 
572 Werneburg, 2011; Werneburg, 2012). However, B. elegans does not have a skull as flat as

573 chelids, but has a long supraoccipital bone as well as a greater temporal emargination (Gaffney et

574 al., 2011), indicating more area and volume availableto m. adductor mandibulae externus

575 (Dalrymple, 1977; Sterli \& de la Fuente, 2010). The mechanical effects of adductor muscles

576 upon the lower jaw during food capture has been demonstrated in some turtles (Schumacher,

577 1973; Lemell et al., 2000; Lemell et al., 2002; Pfaller et al., 2011). These studies agree that

578 besides acting to close the mouth, the $m$. adductor mandibulae internus executes counter

579 protraction forces to the m. adductor mandibulae externus retraction forces, while m. adductors

580 mandibulae posterior produce medial forces (Fig. 10C and 10D). The contraction of all these

581 muscles together avoid displacements of the mandible and reduce stresses at the articulation

582 (Schumacher, 1973; Lemell et al., 2000; Lemell et al., 2002). The positive allometries of the

583 bones of the lower adductor chamber of B. elegans, therefore, may reflect greater resistance for a

584 more robust musculature of $m$. adductor mandibulae internus and $m$. adductor mandibulae

585 posterior in response to higher forces created by external adductors. Besides, these muscles also

586 play the main role in feeding, as proposed for aquatic feeders (Frazzetta, 1968; Werneburg,

587 2012), in addition to a larger area between the two tips of the maxilla (i.e. SMX a=0.70) and a

588 flattened skull.

589 4.3. Feeding changes over ontogeny in B. elegans

590 Changes in skull shape may be due to habitat differences in which terrestrial turtles (e.g.

591 testudinids) possess higher and shorter skulls while aquatic turtles (e.g. emydids) have flatter and

592 longer skulls (Claude et al., 2004). The changes in skull shape of turtles along ontogeny have

593 been assessed in living species (Dalrymple, 1977; Pfaller et al., 2011). Generally, it is supported

594 that a diet shift occurs from small soft prey to bigger harder ones, in association with higher, 
595 larger and more robust skulls. These, in turn, are more suitable for crushing clams and/or to

596 capture fishes by having a greater gape. The overall aquatic morphology comprises adaptations

597 to suction feeding, which was also discussed by Herrel et al. (2002), and could be the case of $B$.

598 elegans. Firstly because taphonomic studies at Pirapozinho site suggested a riverine ephemerous 599 system (Soares et al., 1980; Fulfaro and Perinotto, 1996; Fernandes \& Coimbra, 2000; Henriques 600 et al., 2002, 2005; Suárez, 2002; Bertini et al., 2006; Henriques, 2006) and fossils that suffered 601 little transportation (Bertini et al., 2006), thus it is more likely that B. elegans has been a semi602 aquatic turtle, similar to the extant freshwater turtles. Secondly, the general pattern observed 603 revealed form and shape changes in both temporal and lateral emargination (upper and lower 604 adductor chamber, respectively): as a whole, B. elegans skull seems to become more 605 emarginated, flattened and longer as it grows, according to the skull shape for aquatic turtles 606 found by Claude et al. (2004), and indicating greater area and volume for muscles attachment. In 607 addition, the deeper temporal emargination of $B$. elegans indicates a greater increase in muscle 608 volume (Kischlat, 1994), thus leading to a stronger bite force (Sterli \& de la Fuente, 2010). This

609 leads us to interpret such changes as related to a shift in diet as individuals grow instead of a shift 610 in habitat.

611 Malvasio et al. (2003) described diet changes in Podocnemis expansa, P. unifilis and P.

612 sexturberculata due to aging, concluding that the latter is a carnivore species, whereas the two 613 former are omnivorous. Whereas $P$. expansa changes its diet becoming more herbivorous, $P$. 614 unifilis remains more balanced with similar ingestion of vegetables and meat (Malvasio et al., 615 2003). Kischlat (1994) suggested that B. elegans might have fed of hard preys and, given the 616 several mollusk and crustacean species described for the Pirapozinho site (Dias-Brito et al., 617 2001), it might have composed the diet of B. elegans. In this context, we agree with Kischlat 
618 (1994) and suggest that smaller juveniles individuals might have fed on less hard and small food

619 items (e.g. snails and small fishes) whereas bigger old specimens fed on harder and larger preys, 620 such as crustaceans and bigger mollusks.

621

622 Although there is a possibility that size differences could be due to sexual dimorphism (R.

623 Hirayama and S. Thomson, pers. comm.) as aforementioned (see Introduction, section 1.2.3), we

624 were not able to assume such assumption. Furthermore, if there is size-related dimorphism, it

625 would imply on potential diet differentiation between adults male and female of B. elegans.

626 Since we were not able to determine size-related sexual dimorphism, such statementis merely

627 speculative.

628 5. Conclusions

629 As Romano \& Azevedo (2007) (for shell material), our data did not show enough 630 morphometrical variation to suggest population differences among our sample. So, we did not

631 have evidence to disprove that the "Tartaruguito" site is composed of a single population of $B$.

632 elegans. However, it is feasible to assume that different generations of individuals were crowded

633 in this locality by the accumulation of corpses due to several drying events as previously

634 suggested by Henriques et al. (2005) and Henriques (2006). Since none B. elegans hatchling

635 were found in the "Tartaruguito" site until now, it might have been preferentially a freshwater

636 foraging area.

637 As regards to the morphometric data, the observed variation and allometries in the skull bones, 638 mainly the PA, QJ, SQ, QU, PO, JU, MX, PAL and PT, as well as PCAs loadings, reflect shape 639 differences in both upper and lower adductor chambers. We interpret this allometric variation as 
640 an indicative of more area attachment and resistance for stronger adductor muscles, which are

641 accompanied by changes in diet during aging, from softer to harder prey, as seen in living

642 turtlesspecies.

643 As regards to the use of images for carrying out morphometrics studies, we conclude that the use

644 of calipers can be replaced by softwares that work on images. ImageJ is a useful and time-saving

645 tool for this matter. However, one needs to beware when measuring straight lines between

646 landmarks that are located in different depths, which result in angled lines against the projection

647 orthogonal plane. Unattention to this detail will lead to assess lower values for a given

648 measurement than its real size.

649 Regarding the approaches applied to our data to deal with missing entries in the matrix (i.e. mean

650 value or iterative imputation), both were useful for answering the questions we raised (i.e. the

651 single population hypothesis), though little different results were obtained (few specimens out of

$65295 \%$ confidence ellipse in mean value approach in contrast with none specimen out of ellipse in

653 iterative imputation approach). However, we recommend the iterative imputation as the most

654 appropriate approach to deal with missing data in paleontological studies on the basis of the

655 statistical assumptions it was developed (a sample-based regression for characters estimation)

656 and the more conservative results.

657 Institutional Abbreviations: AMNH - American Museum of Natural History, New York, NY,

658 United States; LPRP - Laboratório de Paleontologia da Faculdade de Filosofia, Ciências e

659 Letras de Ribeirão Preto, Universidade de São Paulo, Ribeirão Preto, SP, Brazil; MN - Museu

660 Nacional, Universidade Federal do Rio de Janeiro, Rio de Janeiro, RJ, Brazil; MCT - Museu de

661 Ciências da Terra, Departamento Nacional de Produção Mineral, Rio de Janeiro, RJ, Brazil; 
662 MCZ - Museum of Comparative Zoology, Harvard University, Cambridge, MA, United States;

663 MZSP - Museu de Zoologia, Universidade de São Paulo, São Paulo, SP, Brazil.

664 Anatomical abbreviations: PF - prefrontal; FR - frontal; PA - parietal; VO - vomer; PAL 665 palatine; PT - pterygoid; BS - basisphenoid; BO - basioccipital; MX - maxilla; JU - jugal; QJ 666 - quadratojugal; QU - quadrate; PO - postorbital; SQ - squamosal; OP - opisthotic; CO 667 choanal.

668

669

670

671

672

673

674

675

676

677

678

679

680

681

682

683

Measurements abbreviations: TLS - Total length of skull; LPF - Length of prefrontal; LFR Length of frontal; LPA - Length of parietal; LVO - Length of vomer; LPAL - Length of palatine; LPT - Length of pterygoid; LBS - Length of basisphenoid; LBO - Length of basioccipital; LMX - Length of maxilla; LJU - Length of jugal; LQJ - Length of quadratojugal; LQU - Length of quadrate; LPO - Length of postorbital; LSQ - Length of squamosal; TWS - Total width of skull; WPF - Width of prefrontal; WFR - Width of frontal; WPA - Width of parietal; SMX - Stretch of maxilla; WVO - Width of vomer; WCO - Width of choanal; WPAL - Width of palatine; WBS - Width of basisphenoid; WMX - Width of maxilla; WJU - Width of jugal; WQJ - Width of quadratojugal; WPO - Width of postorbital; WOP - Width of opisthotic.

\section{Acknowledgments}

We are grateful to Sergio Azevedo, Deise Henriques, Luciana Carvalho, Lílian Cruz (DGP/MN) and Max Langer (LPRP/USP) for allowingthe loan of the material and/or visits to collections under their care when necessary. Pedro Romano thanks the following people and institutions for facilitating access to collections: E. Gaffney, C. Mehling and F. Ippolito (AMNH); and R. Cassab and R. Machado (MCT). We thank to Gustavo Oliveira (UFRPE) for being part of 
684 Thiago Mariani's undergraduate thesis committee and for making revisions, suggestions, and 685 comments that contributed to this paper. We are also grateful to M. Lambertz (University of 686 Bonn) and C. Mariani for revisions and comments on early versions of the manuscript. Gabriel 687 Ferreira (LPRP/USP), Mirian Menegazzo (Unesp) and Gustavo Oliveira (UFRPE) shared 688 information about Bauru Basin fossil turtle records that were incorporated to figure 1. Torsten

689 Scheyer and a second anonymous reviewer provided comments and insights that greatly 690 improved the manuscript. Preliminary results of this paper composed the undergraduate thesis of 691 Thiago Mariani.

\section{References}

693

694

695

696

697

698

699

700

701

702

703

704

705

706

707

708

709

710

711

712

AERTS P, VAN DAMME J, HERREL A. 2001. Intrinsic mechanics and control of fast craniocervical movements in aquatic feeding turtles. American Zoologist 41:1299-1310. DOI: dx.doi.org/10.1668/0003-1569(2001)041[1299:IMACOF]2.0.CO;2.

AGUILERA OA. 2004. Tesoros Paleontológicos de Venezuela. Urumaco, Patrimonio Natural de la Humanidad. Editorial Arte: Caracas.

ANQUETIN J. 2012. Reassessment of the phylogenetic interrelationships of basal turtles (Testudinata). Journal of Systematic Paleontology 10(1):3-45. DOI: 10.1080/14772019.2011.558928.

BAILEY SE. 2004. A morphometric analysis of maxillary molar crowns of Middle-Late Pleistocene hominins. Journal of Human Evolution 47(3): 183-198. DOI: dx.doi.org/10.1016/j.jhevol.2004.07.001.

BERTINI RJ, SANTUCCI RM, TOLEDO CEV, MENEGAZZO MC. 2006. Taphonomy and depositional history of an Upper Cretaceous turtle-bearing outcrop from the Adamantina Formation, Southwestern São Paulo state. Revista Brasileira de Paleontologia 9(2):181-186.

CADENA EA, BLOCH JI, JARAMILLO CA. 2010. New podocnemidid turtle (Testudines: Pleurodira) from the Middle-Upper Paleocene of South America. Journal of Vertebrate Paleontology 30(2):367-382. DOI: dx.doi.org/10.1080/02724631003621946.

CADENA EA, BLOCH JI, JARAMILLO CA. 2012. New bothremydid turtle (Testudines, Pleurodira) from the Paleocene of Northeastern Colombia. Journal of Paleontology 86(4):688698. DOI: dx.doi.org/10.1666/11-128R1.1. 
713 CADENA EA, KSEPKA DT, JARAMILLO CA, BLOCH JI. 2012. New pelomedusoid turtles 714 from the late Paleocene Cerrejón Formation of Colombia and their implications for phylogeny 715 and body size evolution. Journal of Systematic Paleontology 10(2):313-331. DOI:

716 dx.doi.org/10.1080/14772019.2011.569031.

717 CAMPOS DA, OLIVEIRA GR, FIGUEIREDO RG, RIFF D, AZEVEDO SAK, CARVALHO 718 LB, KELLNER AWA. 2011. On a new peirosaurid crocodyliform from the Upper Cretaceous, 719 Bauru Group, southeastern Brazil. Anais da Academia Brasileira de Ciências 83(1):317-327. 720 DOI: dx.doi.org/10.1590/S0001-37652011000100020.

721 CLAUDE J, PRITCHARD PCH, TONG H, PARADIS E, AUFFRAY JC. 2004. Ecological

722

723

724

725

726

727

728

729

730

731

732

733

734

735

736

737

738

739

740

741

742

743

744

745

746 correlates and evolutionary divergence in the skull of turtles: a geometric mophometric assessment. Systematic Biology 53(6):933-962. DOI: 10.1080/10635150490889498.

CONGDON JD, NAGLE RD, KINNEY OM, SELS RCVL, QUINTER T, TINKLE DW. 2003. Testing hypotheses of aging in long-lived painted turtles (Chrysemys picta). Experimental Gerontology 38:765-772.

DALRYMPLE GH. 1977. Intraspecific variation in the cranial feeding mechanism of turtles of the genus Trionyx (Reptilia, Testudines, Trionychidae). Journal of Herpetology 11(3):255-285. DOI: $10.2307 / 1563241$.

DEPECKER M, RENOUS S, PENIN X, BERGE C. 2005. Procrustes analysis: a tool to understand shape changes of the humerus in turtles (Chelonii). Comptes Rendus Palevol 5: 509518.

DEPECKER M, BERGE C, PENIN X, RENOUS S. 2006. Geometric morphometrics of the shoulder girdle in extant turtles (Chelonii). Journal of Anatomy 208: 35-45.

DE BROIN F. 1991. Fossil turtles from Bolivia. In: Suarez-Soruco R. Fossiles y facies de Bolívia - Vol. I Vertebrados. Revista Técnica de YPFB, 12(3-4): 509-527.

DE LA FUENTE MS, STERLI J, MANIEL I. 2014. Origin, evolution and biogeographic history of South American turtles. Springer Earth System Sciences.

FERNANDES LB, COIMBRA AM. 2000. Revisão estratigráfica da parte oriental da Bacia Bauru (Neocretáceo). Revista Brasileira de Geociências 30(4):717-728.

FERREIRA GS, RINCÓN AD, SOLÓRZANO A, LANGER MC. 2015. The last marine pelomedusoids (Testudines: Pleurodira): a new species of Bairdemys and the paleoecology of Stereogyina. PeerJ 3:e1063. DOI: 10.7717/peerj.1063.

FRANÇA MAG, LANGER MC. 2005. A new freshwater turtle (Reptilia, Pleurodira, Podocnemidae) from the Upper Cretaceous (Maastrichtian) of Minas Gerais, Brazil. Geodiversitas 27: 391-411. 
747 FRAZZETTA TH. 1968. Adaptative problems and possibilities in the temporal fenestration of 748 tetrapod skulls. Journal of Morphology 125:145-157.

749 FULFARO VJ, PERINOTTO JAJ. 1996. A Bacia Bauru: estado da arte. Boletim do Quarto 750 Simpósio sobre o Cretáceo do Brasil, UNESP, Rio Claro, SP: 297-303.

751 FUTUYMA DJ. 1993. Biologia evolutiva. 2 ed. Ribeirão Preto: FUNPEC-RP.

752 GAFFNEY ES. 1972. An Illustred Glossary of Turtle Skull Nomeclature. American Museum 753 Novitates 2486:33pp.

754 GAFFNEY ES. 1975. A phylogeny and classification of the higher categories of turtles. Bulletin 755 of the Americam Museum of Natural History 155(5):387-436.

756 GAFFNEY ES. 1979. Comparative Cranial Morphology of Recent and Fossil Turtles. Bulletin of 757 the American Museum of Natural History 164(2):65-376.

758

759

760

761

762

763

764

765

766

767

768

769

770

771

772

773

774

775

776

777

778

GAFFNEY ES, MEYLAN PA, WOOD RC, SIMONS E, CAMPOS DA. 2011. Evolution of the side-necked turtles: the family Podcnemididae. Bulletin of the American Museum of Natural History 350: 237pp. DOI: dx.doi.org/10.1206/350.1.

GAFFNEY ES., MEYLAN PA, WYSS AR. 1991. A computer assisted analysis of the relationships of the higher categories of turtles. Cladistics 7:313-335. DOI: 10.1111/j.10960031.1991.tb00041.x.

GAFFNEY ES, SCHEYER TM, JOHNSON KG, BOCQUENTIN J, AGUILERA OA. 2008. Two new species of the side necked turtle genus, Bairdemys (Pleurodira, Podocnemididae), from the Miocene of Venezuela. Palaontoloqische Zeitschrift 82(2):209-229.

GAFFNEY ES, TONG H, MEYLAN PA. 2006. Evolution of the sidenecked turtles: the families Bothremydidae, Euraxemydidae and Araripemydidae. Bulletin of the American Museum of Natural History 300:698pp. DOI: dx.doi.org/10.1206/00030090(2006)300[1:EOTSTT]2.0.CO;2.

GOULD SJ. 1966. Allometry and size in ontogeny and phylogeny. Biological Reviews 41:587640. DOI: 10.1111/j.1469-185X.1966.tb01624.x.

GOULD SJ. 1979. An allometric interpretation of species-area curver: the meaning of the coefficient. The American Naturalist 114(3):335-343.

HAMMER Ø, HARPER DAT, RYAN PD. 2001. Past: Palentological Statistics software package for education and data analysis. Palaeontologia Electronica 4(1):9pp.

HAMMER Ø, HARPER DAT. 2006. Paleontological Data Analysis. Blackwell.

HENNIG, W. 1966. Phylogenetic Systematics. Urbana: University of Illinois Press. 
779

780

781

782

783

784

785

786

787

788

789

790

791

792

793

794

795

796

797

798

799

800

801

802

803

804

805

806

807

808

809

810

HENRIQUES DDR. 2006. Sítio fossilífero de Pirapozinho: estudo de aspectos taxonômicos através da análise básica e do exame de tomografia computadorizada. D. Phil. Thesis. Museu Nacional - Universidade Federal do Rio de Janeiro.

HENRIQUES DDR, SUÁREZ JM, AZEVEDO SAK, CAPILLA R, CARVALHO LB. 2002. A brief note on the paleofauna of "Tartaruguito" site, Adamantina Formation, Bauru Group, Brazil. Anais da Academia Brasileira de Ciências 74(2): 366.

HENRIQUES DDR, AZEVEDO SAK, CAPILLA R. SUÁREZ JM. 2005. The Pirapozinho Site - a taphofacies study. Journal of Vertebrate Paleontology 25:69A.

HERMANSON G, FERREIRA GS, LANGER MC. 2016. The largest Cretaceous podocnemidoid turtle (Pleurodira) revealed by an isolated plate from the Bauru Basin, southcentral Brazil. Historical Biology 28(8):1-8. DOI: dx.doi.org/10.1080/08912963.2016.1248434

HERREL A, O'REILLY JC, RICHMOND AM. 2002. Evolution of bite performance in turtles. Journal of Evolutionary Biology 15:1083-1094. DOI: 10.1046/j.1420-9101.2002.00459.x.

HUXLEY JS. 1950. Relative growth and form transformation. Proceedings of the Royal Society of London B 137:465-469. DOI: 10.1098/rspb.1950.0055.

HUXLEY JS, TEISSIER G. 1936. Terminology of Relative Growth. Nature 137:780-781. DOI: $10.1038 / 137780 \mathrm{~b} 0$.

ILIN A, RAIKO T. 2010. Practical approaches to Principal Components Analysis in the presence of missing values. Journal of Machine Learning Research 11:1957-2000.

JARAMILLO CA, BAYONA G, PARDO-TRUJILLO A, RUEDA M, TORRES V, HARRINGTON GJ, MORA G. 2007. The palynology of the Cerrejón formation (Upper Paleocene) of northern Colombia. Palynology 31(1):153-189. DOI: 10.1080/01916122.2007.9989641.

JOLICOEUR P, MOSIMANN JE. 1960. Size and shape variation in the painted turtle: a Principal Component Analysis. Growth 24: 339-354.

JONES MEH, WERNEBURG I, CURTIS N, PENROSE R, O’HIGGINS P, FAGAN MJ, EVANS SE. 2012. The head and neck anatomy of sea turtles (Cryptodira: Chelonioidea) and skull shape in Testudines. PloS ONE 7(11):e47852. DOI: 10.1371/journal.pone.0047852. DOI: 10.1371/journal.pone.0047852.

JOYCE WG. 2007. Phylogenetic relationships of Mesozoic turtles. Bulletin of Peabody Museum of Natural History 48(1):3-102. DOI: dx.doi.org/10.3374/0079032X(2007)48[3:PROMT]2.0.CO;2. 
811 JOYCE WG, LYSON TR. 2010. A neglected lineage of North American turtles fills a major gap 812 in the fossil record. Paleontology 53(2): 241-248. DOI: 10.1111/j.1475-4983.2009.00929.x

813 KISCHLAT EE. 1994. Observações sobre Podocnemis elegans Suaréz (Chelonii, Pleurodira, 814 Podocnemididae) do Neocretáceo do Brasil. Acta Geologica Leopoldensia, 39: 345-351.

815 KISCHLAT EE, BARBARENA, MC, TIMM, LL. 1994. Considerações sobre a queloniofauna 816 do Grupo Bauru, Neocretáceo do Brasil [Boletim do Simpósio sobre o Cretáceo do Brasil, Rio 817 Claro: Universidade Estadual Paulista. 105-107.

818 KISCHLAT EE. 2015. A new pleurodire turtle (Chelonii) from Adamantina Formation (Bauru 819 Group), Upper Cretaceous of Brazil. PeerJ PrePrints 3:e1075. DOI:

$82010.7287 /$ peerj.preprints.873v1.

821 KLINGER RC, MUSICK JA. 1995. Age and growth of loggerhead turtles (Caretta caretta) from 822 Chesapeake Bay. Copeia 1:204-209.

823 KRZANOWSKI WJ. 1979. Between-Groups comparison of Principal Components. Journal of 824 the American Statistical Association 74: 703-707.

825 KRZANOWSKI WJ. 1979. Between-Groups comparison of Principal Components - some 826 sampling results. Journal of Statistical Computation Simulation 15: 141-154.

827 LEMELL P, BEISSER CJ, WEISGRAM J. 2000. Morphology and function of the feeding 828 apparatus of Pelusios castaneus (Chelonia; Pleurodira). Journal of Morphology 244:127-135. 829 DOI: 10.1002/(SICI)1097-4687(200005)244:2<127::AID-JMOR3>3.0.CO;2-U.

830 LEMELL P, LEMELL C, SNELDERWAARD P, GUMPENBERGER M, WOCHESLÄNDER 831 R, WEISGRAM J. 2002. Feeding patterns in Chelus fimbriatus (Pleurodira: Chelidae). The 832 Journal of Experimental Biology 205:1495-1506. PubMed: 11976360.

833 LYSON TR, JOYCE WG. 2009. A new species of Palatobaena (Testudines: Baenidae) and a 834 maximum parsimony and bayesian phylogenetic analysis of Baenidae. Journal of Paleontology 835 83(3): 457-470. DOI: dx.doi.org/10.1666/08-172.1.

836 MARIANI TF, ROMANO PSR. 2014. Quando não podemos usar paquímetro: ImageJ como 837 ferramenta para obtenção de dados morfométricos em fósseis [abstract no. 61]. Boletim de 838 Resumos do IX Simpósio Brasileiro de Paleontologia de Vertebrados.

839 MALVASIO A, SOUZA AM., MOLINA FB, SAMPAIO FA. 2003. Comportamento e 840 preferência alimentar em Podocnemis expansa (Schweigger), P. unifilis (Troschel) e $P$. 841 sextubeculata (Cornalia) em cativeiro (Testudines, Pelomedusidae). Revista Brasileira de 842 Zoologia, 20(1):161-168. DOI: dx.doi.org/10.1590/S0101-81752003000100021. 
843 MENEGAZZO MC, BERTINI RJ, MAZINI FF. 2015. A new turtle from the Upper Cretaceous

844 Bauru Group of Brazil, updated phylogeny and implications for age of the Santo Anastácio

845 Formation. Journal of South American Earth Science 58: 18-32. DOI:

846 10.1016/j.jsames.2014.12.008.

847 MINGOTI SA. 2013. Análise de dados através de métodos de estatística multivariada: uma 848 abordagem aplicada. Editora UFMG.

849 MURPHY EC, HOGANSON J, JOHNSON K. 2003. Lithostratigraphy of the Hell Creek

850 Formation of North Dakota. In: Hartman JH, Johnson KR, and Nichols DJ ed, The Hell Creek

851 Formation and Cretaceous-Tertiary Boundary in the Great Plains: An Integrated Continental

852 Record of the End of the Cretaceous. The Geological Society of America, Special Paper 361. 985334.

854 NORELL MA, WHEELER WC. 2003. Missing entry replacement data analysis: a replacement 855 approach to dealing with missing data in paleontological and total evidence data sets. Journal of 856 Vertebrate Paleontology 23(2): 275-283.

857 OLIVEIRA GR. 2011. Filogenia e descrição de novos Podocnemididae (Pleurodira:

858 Pelomedusoides). D. Phil. Thesis. Museu Nacional - Universidade Federal do Rio de Janeiro.

859 OLIVEIRA GR, ROMANO PSR. 2007. Histórico dos achados de tartarugas fósseis do Brasil. 860 Arquivos do Museu Nacional 65(1):113-133.

861 PARSONS TS, WILLIAMS EE. 1961. Two Jurassic turtle skulls: a morphological study.

862 Bulletin of the Museum of Comparative Zoology 125(3):41-107.

863 PERES-NETO PR, JACKSON DA, SOMERS KM. 2003. Giving meaningful interpretation to 864 ordination axes: assessing loading significance in Principal Component Analysis. Ecology 84(9): $8652347-2363$.

866 PFALLER JB, GIGNAC PM, ERICKSON GM. 2011. Ontogenetic changes in jaw-muscle 867 architecture facilitate durophagy in turtle Sternotherus minor. Journal of Experimental Biology 868 214:1655-1667. DOI: 10.1242/jeb.048090.

869 PFALLER JB, HERRERA ND, GIGNAC PM, ERICKSON GM. 2010. Ontogenetic scaling of 870 cranial morphology and bite-force generation in the loggerhead musk turtle. Journal of Zoology 871 280:280-289. DOI: 10.1111/j.1469-7998.2009.00660.x.

872 PRICE IL. 1953. Os quelônios da Formação Bauru, Cretáceo terrestre do Brasil meridional. Rio 873 de Janeiro: Departamento Nacional de Produção Mineral/Divisão de Geologia e Mineralogia, 874 34pp. (Boletim 147). 
875 RABI M, ZHOU CF, WINGS O, GE S, JOYCE WG. 2013. A new xinjiangchelyid turtle from 876 the Middle Jurassic of Xinjiang, China and the evolution of the basipterygoid process in 877 Mesozoic turtles. BMC Evolutionary Biology 13:203. DOI: 10.1186/1471-2148-13-203.

878 RASBAND WS. 1997. ImageJ, U.S.National Institutes of Health, Bethesda, Maryland, USA.

879 Avaiable at https://imagej.nih.gov/ij/1997-2012.

880 RIEPPEL O. 1993. Patterns of Diversity in the Reptilian Skull. In: Hanken J, Hall BK, The Skull, 881 Vol. 2: Patterns of Structural and Systematic Diversity. Chicago: The University of Chicago 882 Press, 344-390.

883 RIFF D, ROMANO PSR, OLIVEIRA GR, AGUILERA OA. 2010. Neogene crocodile and turtle 884 fauna in northern South America. In: Hoorn C, Wesselingh FP ed. Amazonia, Landscape and Species Evolution: A Look into the Past. Wiley-Blackwell Publishing. 259-280. ROMANO PSR. 2008. An unusual specimen of Bauruemys elegans and its implication for the taxonomy of the side-necked turtles from Bauru Basin (Upper Cretaceous of Brazil). Journal of Vertebrate Paleontology 28 (suppl. 3): 133A-134A.

ROMANO PSR. 2010. Evolução do crânio em Pelomedusoides (Testudines, Pleurodira). D. Phil. Thesis. Museu Nacional - Universidade Federal do Rio de Janeiro.

ROMANO PSR, AZEVEDO SAK. 2006. Are extant podocnemidid turtles relicts of a widespread Cretaceous ancestor? South American Journal of Herpetology 1(3):175-184. DOI: 10.2994/1808-9798(2006)1[175:AEPTRO]2.0.CO;2.

ROMANO PSR, AZEVEDO SAK. 2007. Morphometric analysis of the Upper Cretaceous brazilian side-necked turtle Bauruemys elegans (Suárez, 1969) (Pleurodira, Podocnemididae). Arquivos do Museu Nacional 65(4):395-402.

ROMANO PSR, GALLO V, RAMOS RRC, ANTONIOLI L. 2014. Atolchelys lepida, a new side-necked turtle from the Early Cretaceous of Brazil and the age of Crown-Pleurodira. Biology Letters 10: 20140290. DOI: 10.1098/rsbl.2014.0290.

ROMANO PSR, OLIVEIRA GR, AZEVEDO SAK, CAMPOS DA. 2009. Lumping the podocnemidid turtles species from Bauru Basin (Upper Cretaceous of Southeastern of Brazil) [abstract no. 38]. Gaffney Turtle Symposium Abstract Volume: 141-152.

903 ROMANO PSR, OLIVEIRA GR, AZEVEDO SAK, KELLNER AWA, CAMPOS DA. 2013. 904 New information about Pelomedusoides (Testudines: Pleurodira) from the Cretaceous of Brazil. 905 In: Brinkman D, Holroyd P, Gardner J, ed. Morphology and evolution of turtles. Vertebrate 906 Paleobiology and Paleoanthropology Series. Dordrecht, The Netherlands: Springer, 261-275. 
907 SÁNCHEZ-VILLAGRA MR, AGUILERA OA. 2006. Neogene Vertebrates from Urumaco, 908 Falcón State, Venezuela: Diversity and Significance. Journal of Systematic Palaeontology 909 4(3):213-220. DOI: 10.1017/S1477201906001829.

910 SÁNCHEZ-VILLAGRA MR, WINKLER JD. 2006. Cranial variation in Bairdemys turtles

911 (Podocnemididae: Miocene of the Caribbean region) and description of new material from

912 Urumaco, Venezuela. Journal of Systematic Paleontology 4(3):241-253. DOI:

$91310.1017 / \mathrm{S} 1477201906001891$.

914 SCHUMACHER GH. 1973. The head muscles and hyolaryngeal skeleton of turtles and 915 crocodilians. In: Gans C, Biology of Reptilia, vol. 4: Morphology D. London: Academic Press, 916 101-199.

917 SHINE RS, IVERSON JB. 1995. Patterns of survival, growth and maturation in turtles. Oikos 918 72(3):343-348. DOI: 10.2307/3546119.

919 SMITH KK. 1993. The form of the feeding apparatus in terrestrial vertebrates: studies of 920 adaptation and constraint. In: Hanken J, Hall BK, The Skull, Vol. 3:Functional and Evolutionary 921 Mechanisms. Chicago: The University of Chicago Press, 150-196.

922 SOARES PC, LANDIM PMB, FULFARO VJ, NETO AFS. 1980. Ensaio de caracterização 923 estratigráfica do Cretáceo no estado de São Paulo: Grupo Bauru. Revista Brasileira de 924 Geociências 10:177-185.

925 SOMERS KM. 1989. Allometry, Isometry and Shape in Principal Components Analysis. 926 Systematic Zoology 38(2):169-173.

927 STERLI J, DE LA FUENTE MS. 2010. Anatomy of Condorchelys antiqua Sterli, 2008, and the 928 origin of the modern jaw closure mechanism in turtles. Journal of Vertebrate Paleontology 929 30(2):351-366. DOI: 10.1080/02724631003617597.

930 STERLI J, MÜLLER J, ANQUETIN J, HILGER A. 2010. The parabasisphenoid complex in 931 Mesozoic turtles and the evolution of the testudinate basicranium. Canadian Journal of Earth 932 Sciences 47:1337-1346. DOI: 10.2307/3546119.

933 STRAUSS RE, ATANASSOV MN, OLIVEIRA JA. 2003. Evaluation of the principal934 component and expectation-maximization methods for estimating missing data in morphometric 935 studies. Journal of Vertebrate Paleontology 23(2): 284-296.

936 SUÁREZ, JM. 1969a. Um nôvo quelônio fóssil da Formação Baurú [abstract no. 153]. 937 Comunicações do Congresso Brasileiro de Geologia, Salvador: Boletim Especial, Salvador, 938 1:87-89.

939 SUÁREZ, JM. 1969b. Um quelônio da Formação Bauru. Boletim da Faculdade de Filosofia, 940 Ciências e Letras de Presidente Prudente 2:35-54. 
941 SUÁREZ, JM. 1969c. Um quelônio da Formação Bauru [abstract no. 12]. Anais do Congresso 942 Brasileiro de Geologia, Salvador. 167-176.

943 SUÁREZ JM. 2002. Sítio fossilífero de Pirapozinho, SP - Extraordinário depósito de quelônios 944 do Cretáceo. In: Schobbenhaus C, Campos DA, Queiroz ET, Winge M, Berbert-Born M. Sítio 945 geológicos e paleontológicos do Brasil.

946 VAN DAMME J, AERTS P. 1997. Kinematics and functional morphology of aquatic feeding in 947 australian snake-necked turtles (Pleurodira; Chelodina). Journal of Morphology 233:113-125. 948 DOI: 10.1002/(SICI)1097-4687(199708)233:2<127::AID-JMOR4>3.0.CO;2-3.

949 WERNEBURG I. 2011. The cranial musculature of turtles. Palaentologia eletronica 14(2):99p; 950 palaeo-electronica.org/2011_2/254/index.html.

951 WERNEBURG I. 2012. Temporal bone arrangements in turtles: an overview. Journal of 952 Experimental Zoology 318:235-249. DOI: 10.1002/jez.b.22450.

953 WERNEBURG I. 2013. The tendinous framework in the temporal skull region of turtles and 954 considerations about its morphological implications in amniotes: a review. Zoological Science 955 30:141-153. DOI: 10.2108/zsj.30.141.

956 WERNEBURG I, WILSON LAB, PARR WCH, JOYCE WG. 2014. Evolution of neck vertebral 957 shape and neck retraction at the transition to Modern Turtles: an integrated geometric 958 morphometric approach. Systematic Biology 0(0): 1-18. DOI: 10.1093/sysbio/syu072.

959 WINGS O, RABI M, SCHNEIDER JW, SCHWERMANN L, SUN G, ZHOU CF, JOYCE WG. 960 2012. An enormous Jurassic turtle bone bed from the Turpan Basin of Xinjiang, China.

961 Naturwissenschaften 99:925-935. DOI: 10.1007/s00114-012-0974-5. 


\section{Figure 1}

Fossil turtle localities in Bauru Basin

Lithostratigraphical map of the oriental part of the Bauru Basin showing the fossil turtle localities (municipalities). Turtle species are: 1. Cambaremys langertoni (incertae sedis), Pricemys caieira, Peiropemys mezzalirai and Testudines indet. (Oliveira \& Romano, 2007; Romano et al., 2009; Gaffney et al., 2011; Menegazzo, Bertini \& Manzini, 2015); 2. Roxochelys harrisi (nomem dubium; Oliveira \& Romano, 2007; Romano et al., 2009; Menegazzo, Bertini \& Manzini, 2015); 3. Bauruemys brasiliensis (nomem dubium) and Testudines indet. (Oliveira \& Romano, 2007; Menegazzo, 2009; Romano et al., 2009; Menegazzo, Bertini \& Manzini, 2015); 4. Testudines indet. (Menegazzo, 2009; Romano et al., 2009); 5. Testudines indet. (Menegazzo, 2009; Romano et al., 2009); 6. B. brasiliensis and Roxochelys wanderleyi (Oliveira \& Romano, 2007; Romano et al., 2009); 7. Testudines indet. (Menegazzo, 2009; Romano et al., 2009); 8. Testudines indet. (Menegazzo, 2009; Romano et al., 2009); 9. Podocnemididae indet. and Testudines indet. (Menegazzo, 2009; Romano et al., 2009; Kischlat, 2015); 10. Roxochelys sp., R. wanderleyi and Testudines indet. (Menegazzo, 2009; Romano et al., 2009; Romano et al., 2013; Menegazzo, Bertini \& Manzini, 2015); 11. B. elegans and R. wanderleyi (Oliveira \& Romano, 2007; Romano et al., 2009; Menegazzo, Bertini \& Manzini, 2015); 12. Podocnemidinura indet. (Menegazzo, Bertini \& Manzini, 2015); 13. Podocnemidoiae indet. and Testudines indet. (Menegazzo, 2009; Hermanson, Ferreira \& Langer, 2016); 14. R. wanderleyi, B. brasiliensis (nomem dubium) and Testudines indet. (Menegazzo, 2009); 15. Testudines indet. (Menegazzo, 2009); 16. Testudines indet. (Menegazzo, 2009). Abbreviations: GO, Goiás State; MG, Minas Gerais State; MS, Mato Grosso do Sul State; PR, Paraná State; SP, São Paulo State. Scale bar in Km. Map modified from Romano et al. (2009); geology following Fernandes (2004); taxonomy status of species following Romano et al. (2013). 

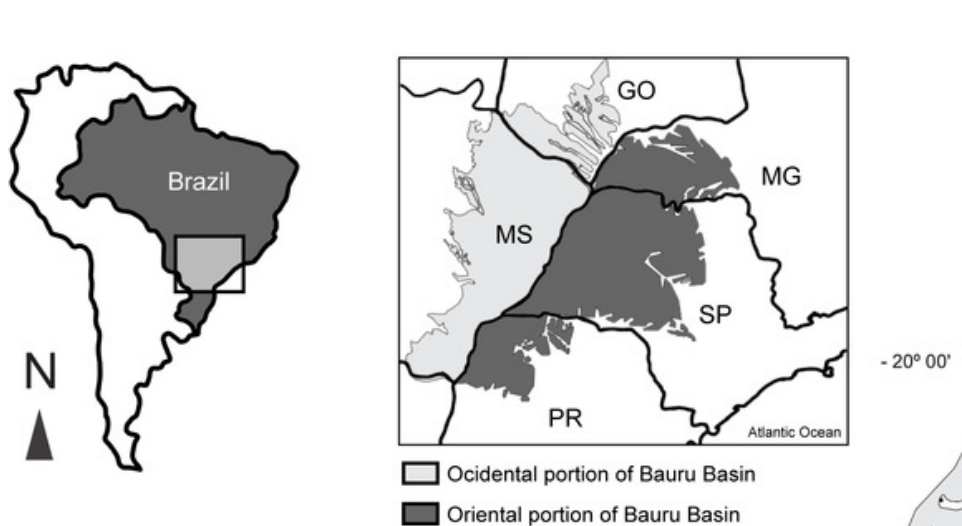

\section{Geology:}

Quaternary deposits

Marilia Formation Uberaba Formation

Presidente Prudente Formation São José do Rio Preto Formation Araçatuba Formation Vale do Rio do Peixe Formation Santo Anastácio Formation Goio Erê Formation

Rio Paraná Formation

Pre-Ks basement $\quad-23^{\circ} 00^{\circ}$

Oriental portion of Bauru Basin

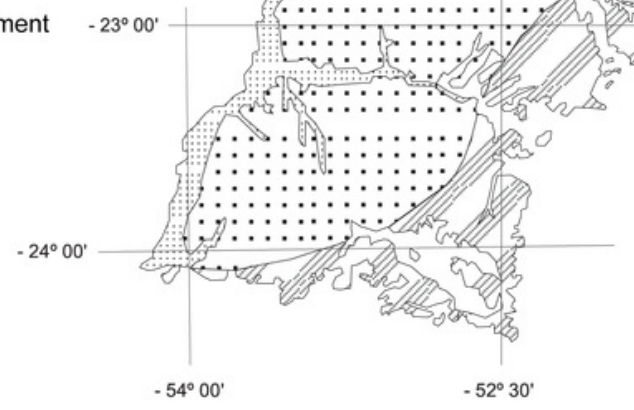

on 2

\section{Localities:}

1. Uberaba/Peirópolis*

2. Colina*

3. São José do Rio Preto

4. Ibirá

5. Votuporanga

6. Araçatuba*
7. Pacaembú/Paulista

8. Adamantina

9. Álvares Machado/Santo

10. Presidente Prudente

11. Pirapozinho*

12. Rubineia
13. Uberaba

14. Mirandópolis/Lavinia

15. Mirassol/Balsamo

16. Catanduva

Type-locality 


\section{Figure 2}

Image of landmarks used as references for taking measurements.

Skull of Bauruemys elegans in (A) dorsal, (B) ventral and (C) right lateral views showing the anatomical nomenclature and the 39 landmarks used for morphometrics analysis. All measurements were taken between two landmarks (see table 2 for vectors description). Abbreviations: bo, basioccipital; bs, basisphenoid; ex, exoccipital; fpp, foramen palatinum posterius; fr, frontal; ju, jugal; mx, maxilla; op, opisthotic; pa, parietal; pal, palatine; pf, prefrontal; pm, premaxilla; po, postorbital; pt, pterygoid; ptp, processus trochlearis pterygoidei; qj, quadratojugal; qu, quadrate; sq, squamosal; so, supraoccipital; vo, vomer. Skull lineation from Gaffney et al. (2011, p.72). 

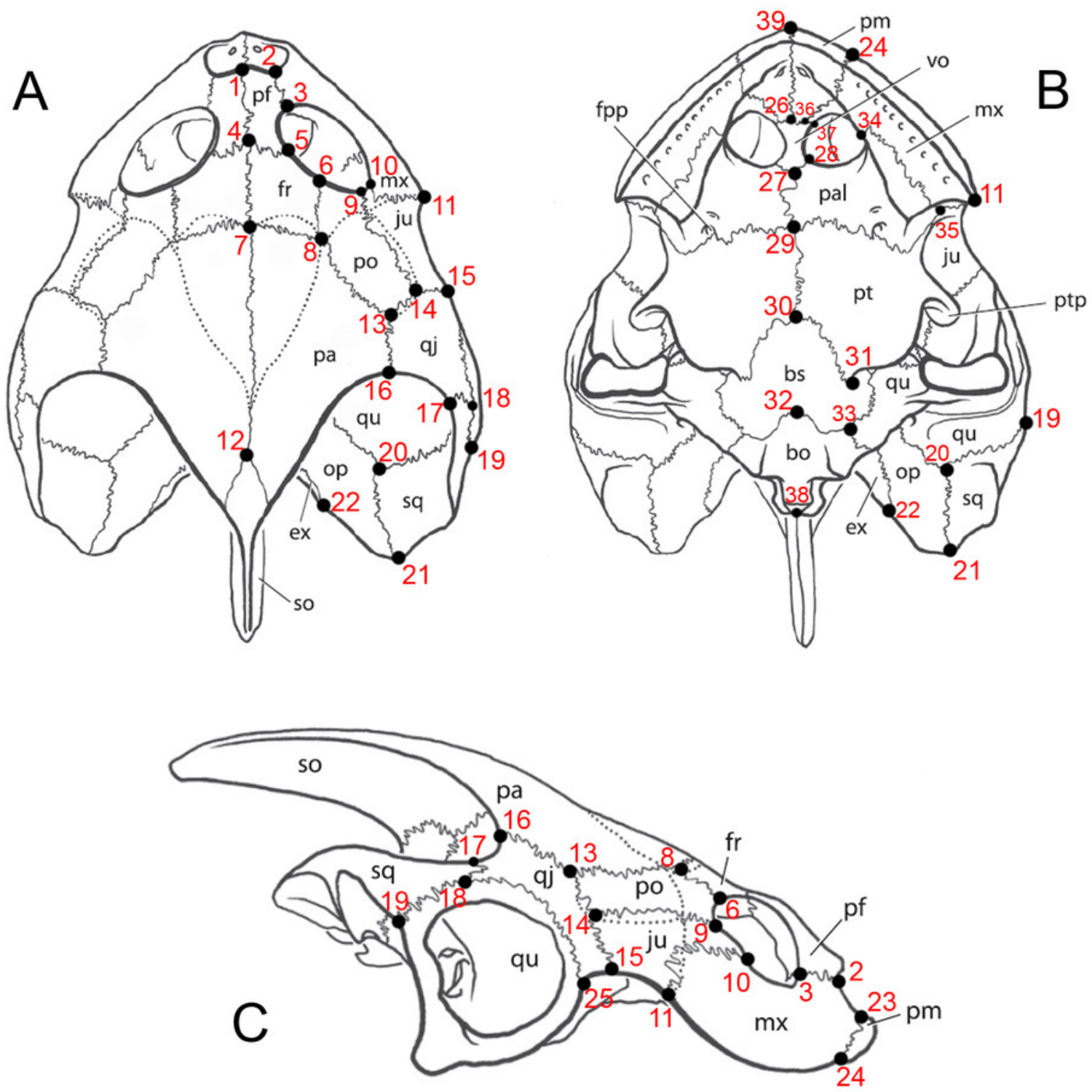


\section{Figure 3}

Allometric graphics: part 1.

Allometries of Bauruemys elegans skull bones: (A) length of parietal (LPA), (B) length of maxilla (LMX), (C), length of jugal (LJU), (D) length of quadrate (LQU), (E) length of squamosal (LSQ), (F) length of pterygoid (LPT), (G) length of postorbital (LPO), (H) stretch of maxilla (SMX), (I) width of quadratojugal (WQJ) (J) and width of parietal (WPA). Angular coefficient (a) and coefficient of correlation ( $r$ ) are shown. Abbreviations: TLS, total length of the skull; TWS, total width of the skull. 

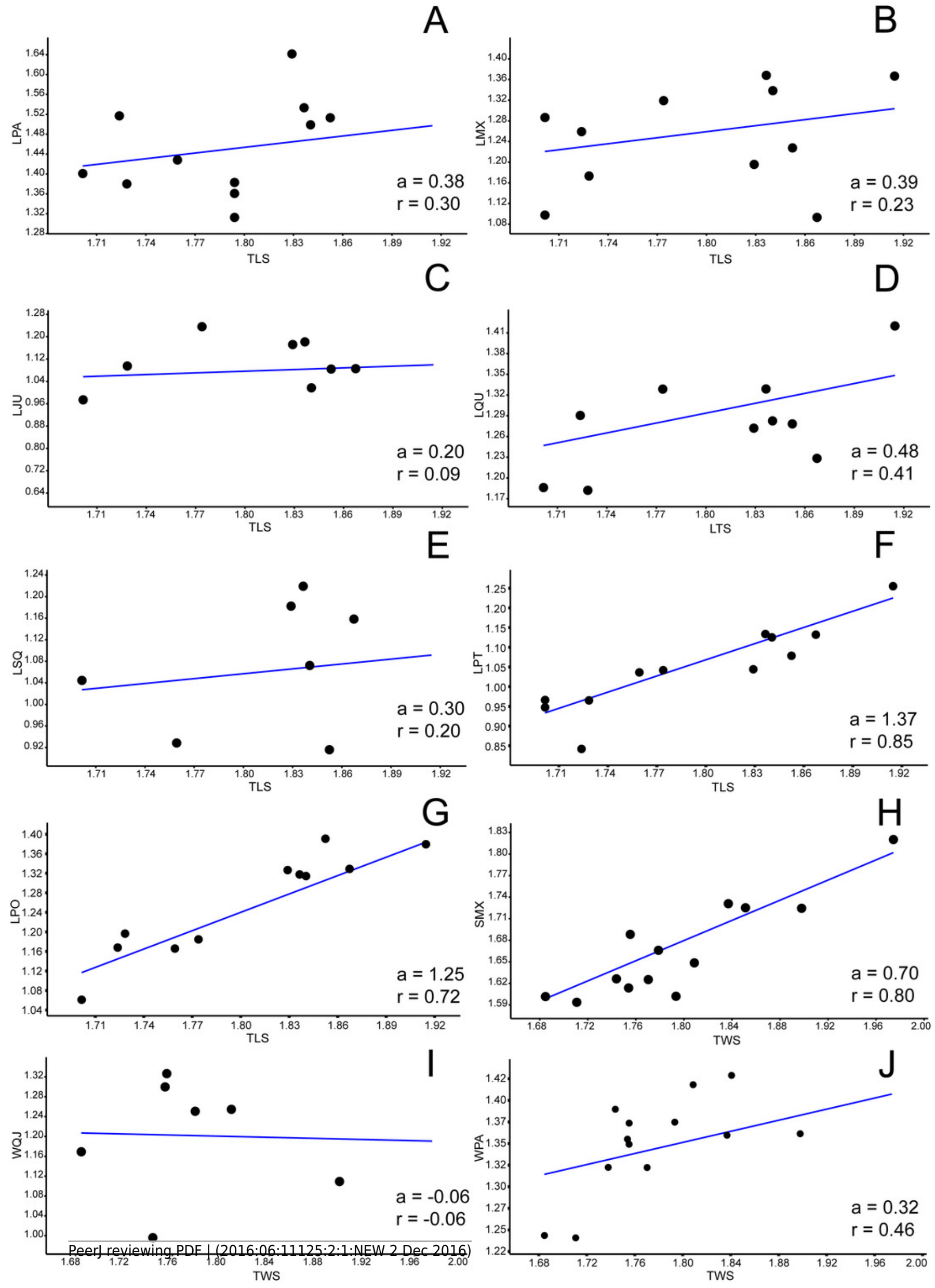


\section{Figure 4}

Allometric graphics: part 2.

Allometries of Bauruemys elegans skull bones: (A) length of basioccipital (LBO), (B) length of basisphenoid (LBS), (C), length of palatine (LPAL), (D) length of frontal (LFR), (E) length of prefrontal (LPF), (F) length of quadratojugal (LQJ), (G) length of vomer (LVO), (H) width of postorbital (WPO), (I) width of opisthotic (WOP) (J) and width of choanal (WCO). Angular coefficient (a) and coefficient of correlation ( $r$ ) are shown. Abbreviations: TLS, total length of the skull; TWS, total width of the skull. 

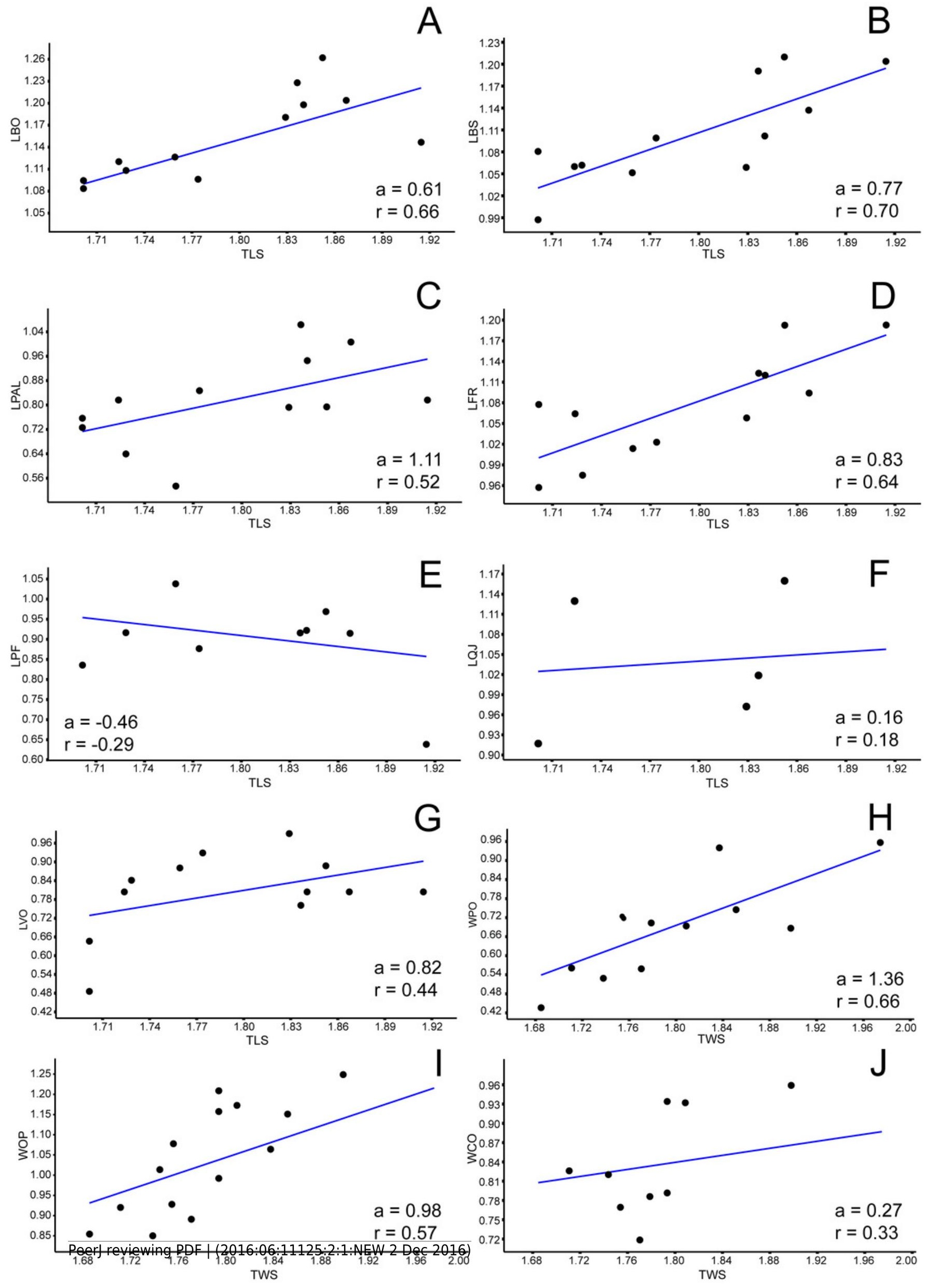


\section{Figure 5}

Allometric graphics: part 3.

Allometries of Bauruemys elegans skull bones: (A) width of maxilla (WMX), (B) width of jugal (WJU), (C), width of frontal (WFR), (D) width of prefrontal (WPF), (E) width of basisphenoid (WBS), (F) width of palatine (WPAL) and (G) width of vomer (WVO). Angular coefficient (a) and coefficient of correlation ( $r$ ) are shown. Abbreviations: TWS, total width of the skull. 

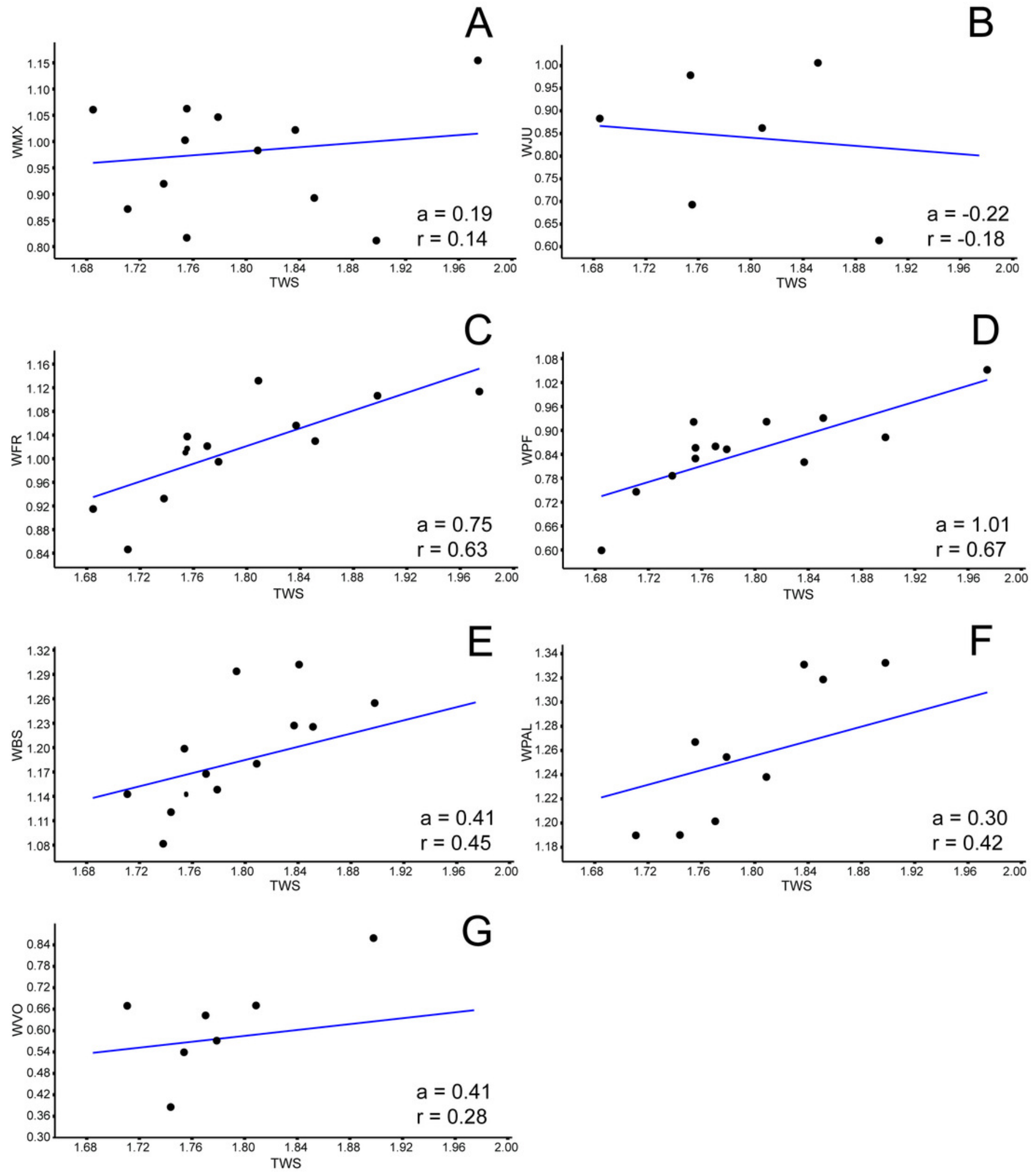


\section{Figure 6}

PCA: raw data.

Principal Components Analysis (PCA) from raw data matrix using mean value substitution approach (A and B) and iterative imputation substitution approach $(C)$ in replacing missing data. The $95 \%$ ellipse is given. 

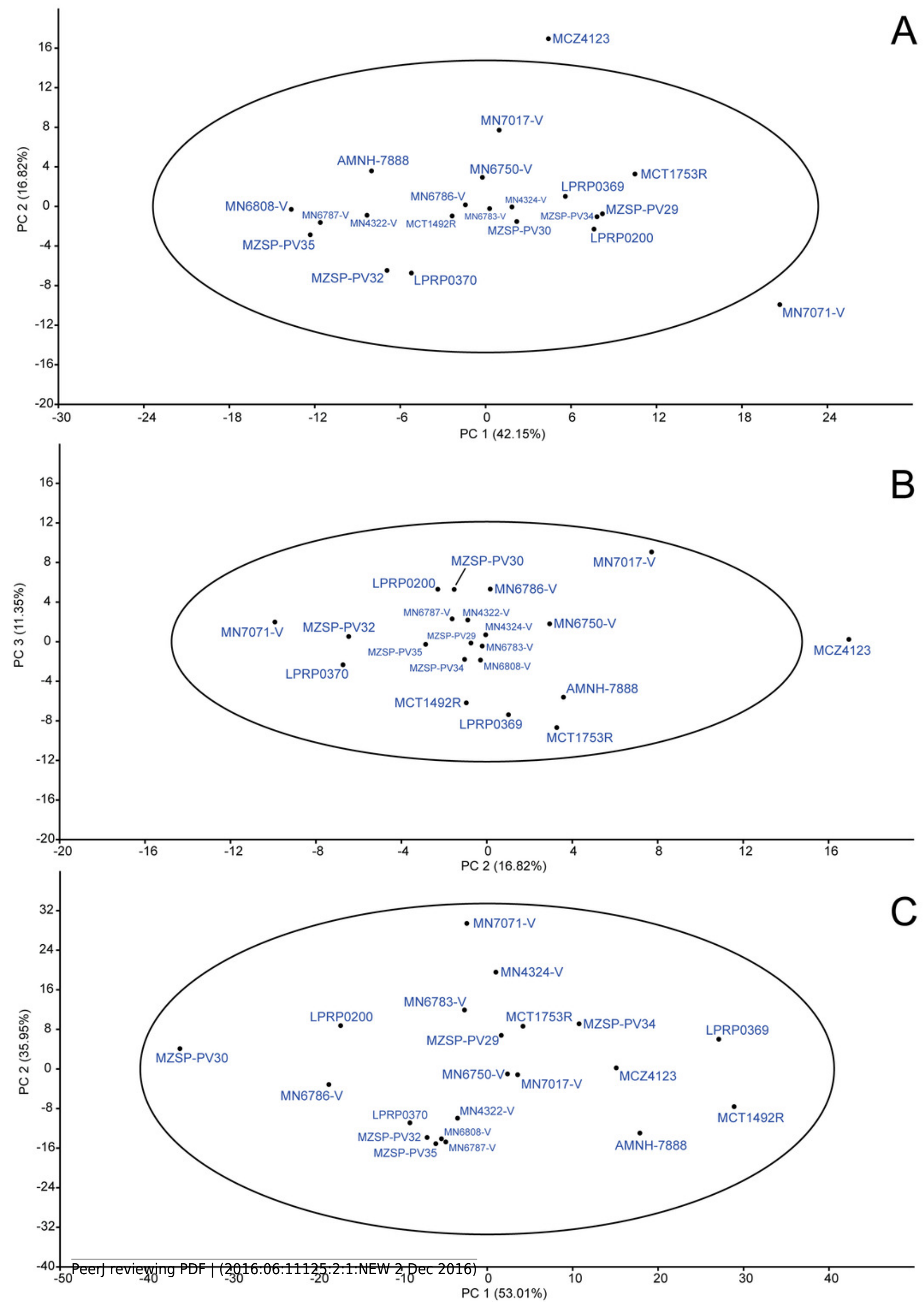


\section{Figure 7}

PCA: proportions data.

Principal Components Analysis (PCA) from proportions data matrix using mean value substitution approach (A) and iterative imputation substitution approach (B) in replacing missing data. The $95 \%$ ellipse is given.
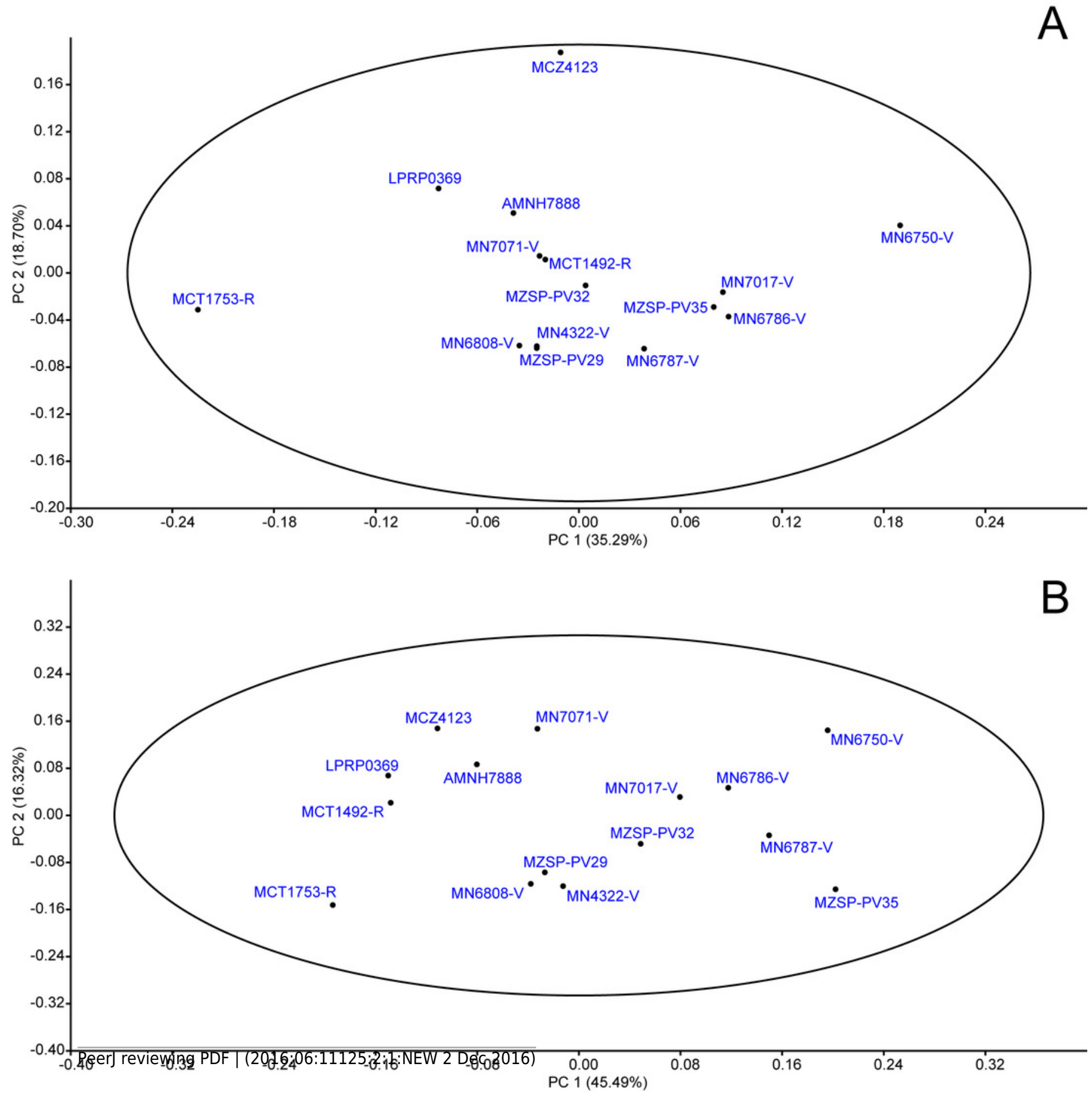


\section{Figure 8}

Comparison of a taphonomically altered skull with two well-preserved skulls of Bauruemys elegans, showing the cheek morphologies observed.

Bauruemys elegans specimens in dorsal view showing the largest MN7071-V specimen (A) in contrast with two smaller, well-preserved narrow-cheeked MN7017-V (B) and wide-cheeked MN4322-V (C) specimens. MN7071-V (A) is larger due to vertical crushing in the mediocaudal portion of the skull, resulting in artificial wide-cheeked morphology. In other specimens, such a taphonomic effect is not observed, indicating that both narrow- (B) and wide-cheeked (C) morphologies are naturally present in $B$. elegans. 


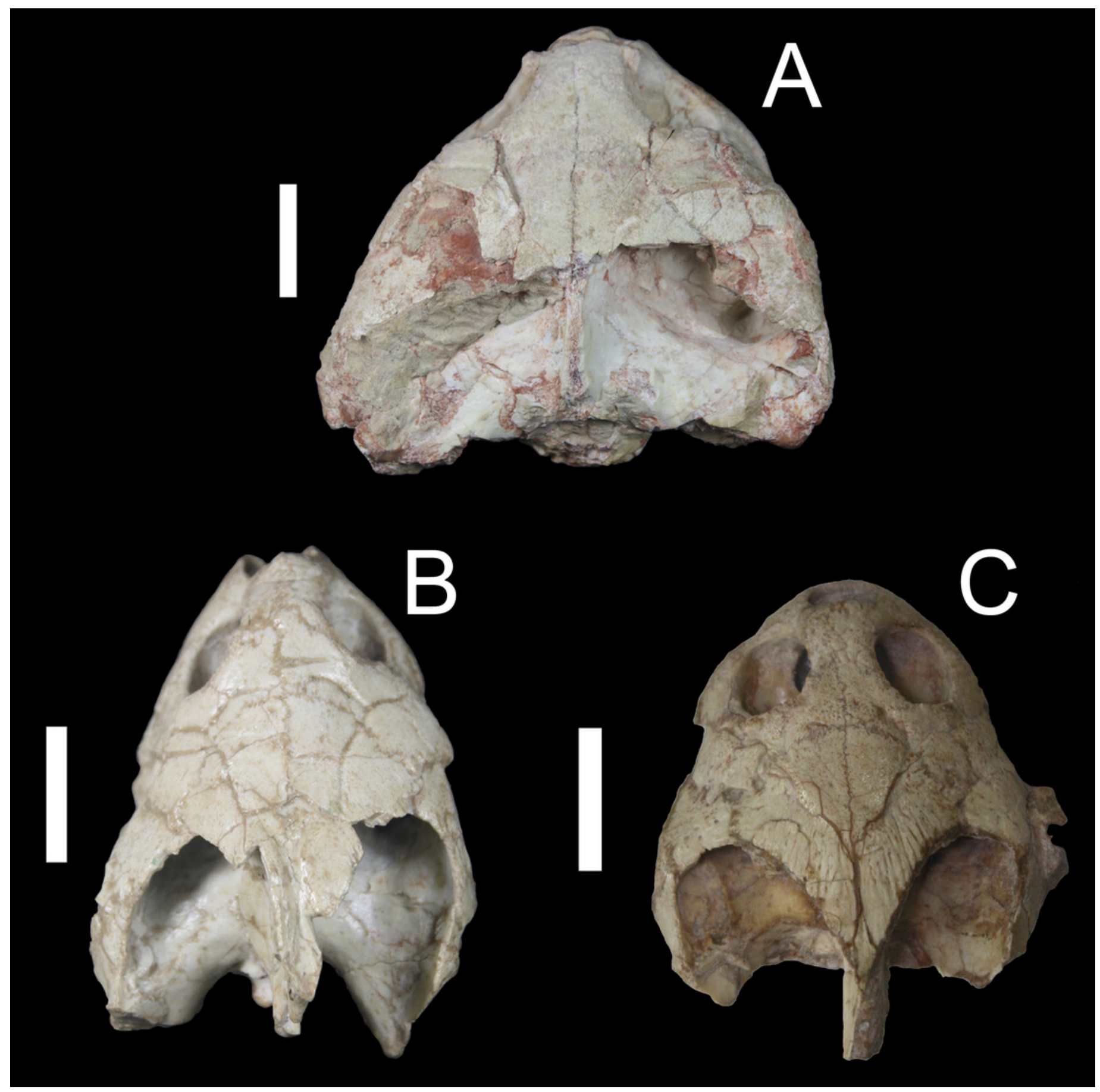




\section{Figure 9}

Evolution of PA-QJ contact and skull roofing in Podocnemidoidea.

Simplified phylogeny of Podocnemidoidea (Bothremydidae + Podocnemidinura) showing the evolution of the contact between parietal (green; PA) and quadratojugal (yellow; QJ), and its relation with the postorbital (red; PO) and skull roofing. Within Bothremydidae, both very emarginated (Cearachelys placidoi) and less emarginated (Taphrosphys congolensis) skulls are present, showing either no contact (C. placidoi) or contact present with small QJ ( $T$. congolensis). Within Podocnemidinura, the contact PA-QJ is present and the skull roofing increased from a less roofed condition, found in Brasilemys josai and Hamadachelys, to a continuous increasingly growing well roofed condition within Podocnemididae, exemplified by Bauruemys elegans, Lapparentemys vilavillensis and Podocnemis unifilis, up to a fully roofed morphology in Peltocephalus. Cearachelys placidoi and T. congolensis modified from Gaffney et al. (2006); Brasilemys josai redrawn from Lapparent de Broin (2000); all others skulls modified from Gaffney et al. (2011). 

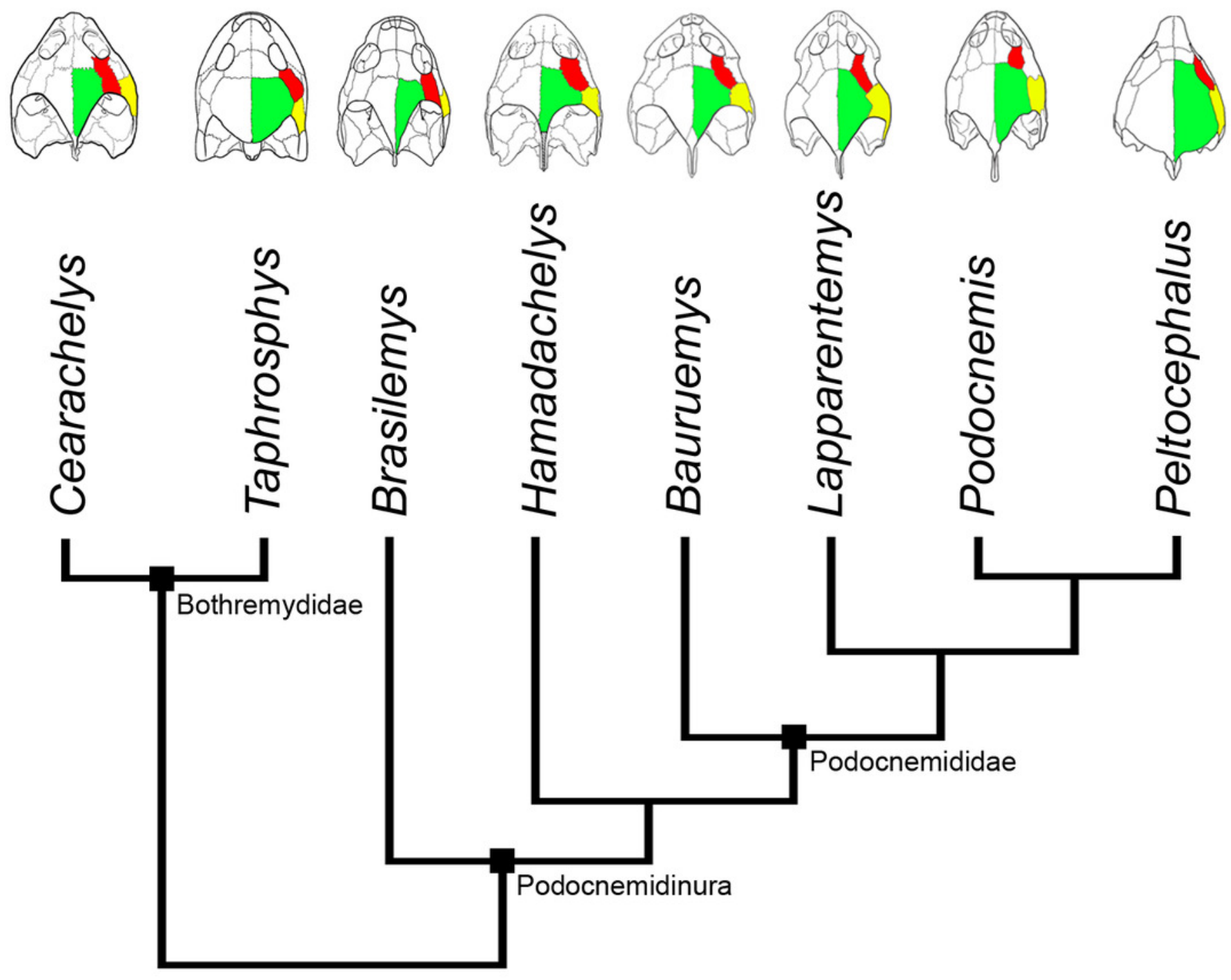


\section{Figure 10}

Sketch of jaw-closing muscles and its vector forces in Podocnemis expansa.

Dorsal ( $A$ and $C$ ) and left lateral ( $B$ and $D$ ) view of the skull of Podocnemis expansa (MZSP0038) showing the muscle attachment places ( $A$ and $B$ ) and the direction vector forces ( $C$ and $D$ ) during jaw closing. The muscles and vectors of $m$. adductor mandibulae externus (green), m. adductor mandibulae posterior (red), m. pterygoideus (blue), and m. depressor mandibulae (yellow) are sketched. Length and thickness of the arrows indicate the relative forces. Abbreviations: art, articular; den, dentary; mx, maxilla; pa, parietal; ptp, processus trochlearis pterygoidei; qj, quadratojugal; qu, quadrate; so, supraoccipital. 

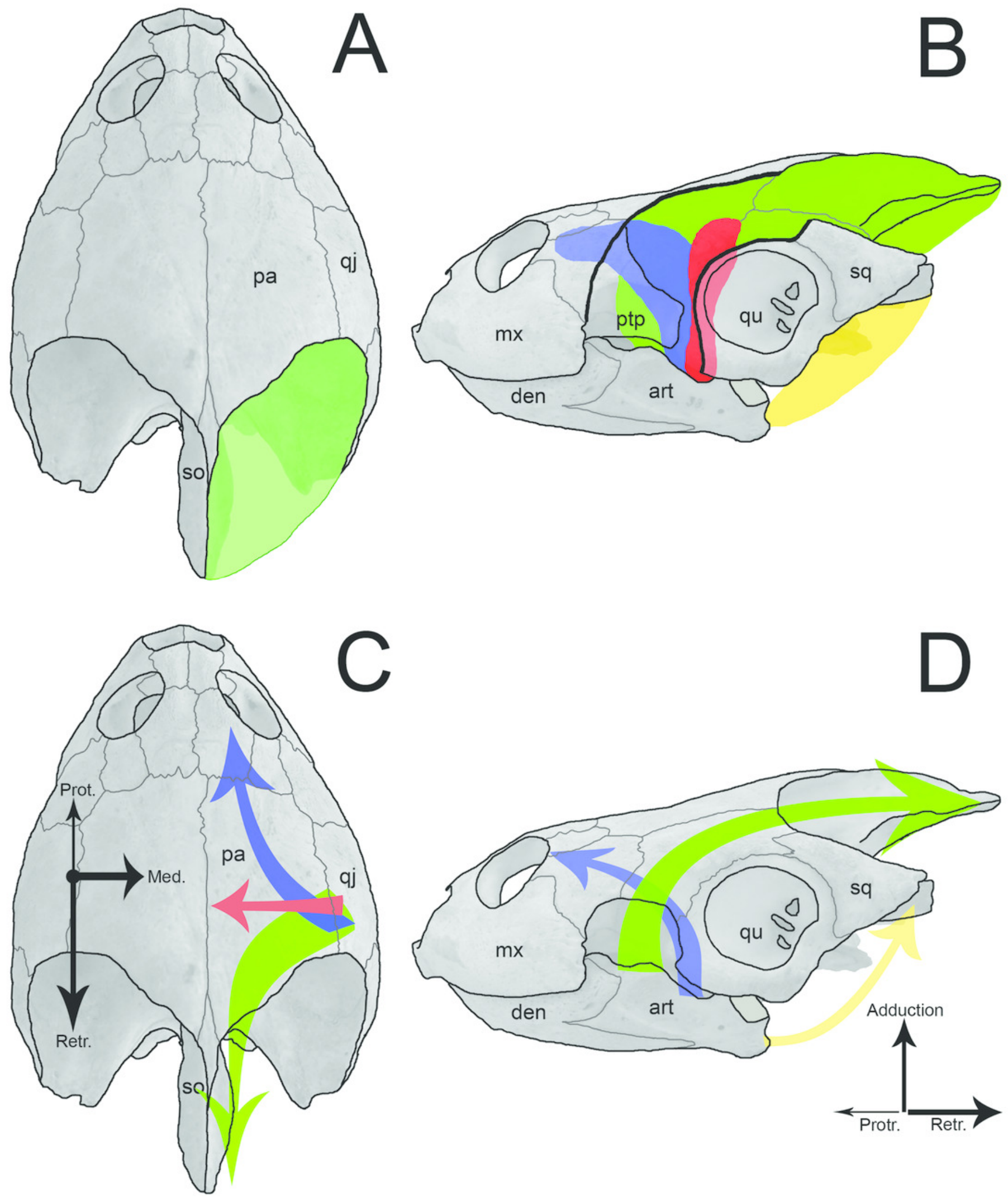


\section{Table $\mathbf{1}$ (on next page)}

ANOVA results for ImageJ and caliper comparisons.

Parameters calculated for each treatment of the ANOVA. Columns 2, 3, and 4 are relative to the caliper (cal) are relative to the ImageJ (ImJ). The last column indicates the $F$ values for each character. Measurements abbreviations: TLS, total length of the skull; TWS total width of the skull; LPF, length of prefrontal; WPF, width of prefrontal; LFR, length of frontal; WFR, width of frontal; LPA, length of parietal; WPA, width of parietal; SMX, stretch of maxilla; LVO, length of vomer; WVO, width of vomer; WCO, width of choannal; LPAL, length of palatine; WPAL, width of palatine; LPT, length of pterygoid; LBS, length of basisphenoid; WBS, width of basisphenoid; LBO, length of basisoccipital; LMX, length of maxilla; WMX, width of maxilla; LJU, length of jugal; WJU, width of jugal; LQJ, length of quadratojugal; WQJ, width of quadratojugal; LQU, length of quadrate; LPO, length of postorbital; WPO, width of postorbital; WOP, width of opisthotic; LSQ, length of squamosal. 


\begin{tabular}{|c|c|c|c|c|c|c|c|}
\hline Char. & N (Cal) & Mean (Cal) & $\sigma($ Cal) & $\mathbf{N}$ (ImJ) & Mean (ImJ) & $\sigma(\operatorname{ImJ})$ & F value \\
\hline TLS & 8 & 63,72 & 10,87 & 8 & 62,26 & 11,36 & 0,069 \\
\hline TWS & 9 & 60,42 & 9,45 & 8 & 64,83 & 13,58 & 0,617 \\
\hline LPF & 9 & 9,78 & 1,26 & 9 & 8,05 & 1,80 & 5,617* \\
\hline WPF & 10 & 6,70 & 1,90 & 10 & 7,55 & 1,83 & 1,04 \\
\hline LFR & 10 & 12,19 & 1,74 & 10 & 11,79 & 2,02 & 0,233 \\
\hline WFR & 10 & 9,64 & 1,63 & 10 & 10,12 & 1,82 & 0,383 \\
\hline LPA & 7 & 25,54 & 4,71 & 7 & 27,35 & 4,83 & 0,504 \\
\hline WPA & 6 & 21,78 & 2,79 & 6 & 22,54 & 3,16 & 0,195 \\
\hline SMX & 9 & 46,46 & 7,12 & 9 & 47,66 & 8,62 & 0,104 \\
\hline LVO & 6 & 5,95 & 1,71 & 7 & 6,59 & 1,31 & 0,596 \\
\hline WVO & 6 & 3,11 & 0,78 & 7 & 3,68 & 0,52 & 1,874 \\
\hline WCO & 5 & 7,53 & 1,31 & 6 & 6,45 & 1,15 & 2,107 \\
\hline LPAL & 7 & 8,26 & 1,25 & 8 & 7,21 & 2,81 & 0,828 \\
\hline WPAL & 7 & 16,90 & 1,91 & 7 & 17,12 & 2,23 & 0,038 \\
\hline LPT & 11 & 11,54 & 2,06 & 12 & 11,69 & 2,75 & 0,228 \\
\hline LBS & 12 & 12,43 & 1,30 & 12 & 12,88 & 1,64 & 0,563 \\
\hline WBS & 11 & 15,58 & 2,32 & 11 & 15,57 & 2,40 & $<0,001$ \\
\hline LBO & 7 & 13,00 & 1,84 & 7 & 13,84 & 1,85 & 0,726 \\
\hline LMX & 10 & 24,28 & 4,20 & 9 & 19,22 & 4,15 & 6,937* \\
\hline WMX & 10 & 10,44 & 2,16 & 9 & 10,18 & 2,26 & 0,065 \\
\hline LJU & 9 & 15,75 & 3,81 & 7 & 13,39 & 2,92 & 1,847 \\
\hline WJU & 3 & 8,31 & 1,20 & 2 & 9,83 & $-* *$ & 2,709 \\
\hline LQJ & 4 & 12,84 & 1,48 & 2 & 11,96 & $-* *$ & 0,366 \\
\hline WQJ & 6 & 16,21 & 4,02 & 3 & 19,65 & 1,72 & 1,921 \\
\hline LQU & 11 & 17,71 & 3,43 & 8 & 21,19 & 3,88 & 4,253 \\
\hline LPO & 9 & 16,57 & 3,30 & 9 & 16,89 & 4,11 & 0,35 \\
\hline WPO & 9 & 5,47 & 1,77 & 8 & 5,44 & 1,73 & 0,002 \\
\hline WOP & 6 & 11,97 & 2,52 & 5 & 10,98 & 3,89 & 0,260 \\
\hline $\begin{array}{l}\text { LSQ } \\
\end{array}$ & 5 & 10,63 & 3,28 & 4 & 12,26 & 3,86 & 0,467 \\
\hline
\end{tabular}

1 Cal: caliper treatment. ImJ: ImageJ treatment. *significant statistically differences. **values not

2 calculated. 


\section{Table 2 (on next page)}

Descriptive statistics of all data.

Descriptive statistics of the three sorts of characters analyzed (total length and width, comprised measurements, and proportions of the measurements), including mean values (Mean), median values (Median), standard deviation values (SD), number of entries (N), and maximum and minimum values (Max-Min). All measurements are expressed in millimeters, except unscaled proportions between two measurements. 


\begin{tabular}{|c|c|c|c|c|c|c|c|}
\hline & CHARACTERS & VECTOR $^{a}$ & $\mathbf{N}$ & Mean & MEdian & SD & Min-MAX \\
\hline \multirow{2}{*}{ 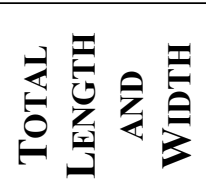 } & TLS & 38-39 & 12 & 63.02 & 63.44 & 10.43 & $50.3-82.15$ \\
\hline & TWS & - & 15 & 63.08 & 58.93 & 11.91 & $48.39-94.27$ \\
\hline \multirow{21}{*}{ 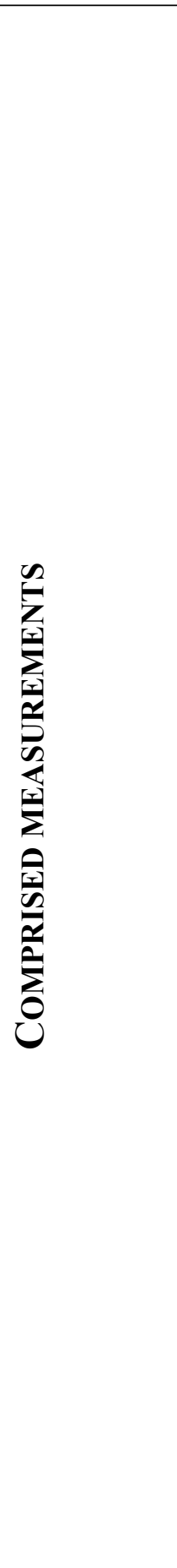 } & LPF & $1-4$ & 15 & 8.35 & 8.31 & 1.69 & $4.35-10.94$ \\
\hline & LFR & $4-7$ & 18 & 12.16 & 12.32 & 2.08 & $9.06-15.59$ \\
\hline & LPA & $7-12$ & 12 & 28.88 & 27.36 & 6.45 & $20.54-43.80$ \\
\hline & LVO & $26-27$ & 10 & 6.67 & 6.84 & 1.95 & $3.06-9.79$ \\
\hline & LPAL & $27-29$ & 13 & 6.91 & 6.22 & 2.33 & $3.42-11.57$ \\
\hline & LPT & $29-30$ & 19 & 11.72 & 11.94 & 2.42 & $6.95-17.99$ \\
\hline & LBS & $30-32$ & 20 & 12.76 & 12.57 & 1.77 & $9.71-16.21$ \\
\hline & LBO & $32-38$ & 13 & 14.16 & 13.38 & 2.12 & $11.13-18.28$ \\
\hline & LMX & $11-24$ & 18 & 18.49 & 18.31 & 4.11 & $12.39-25.68$ \\
\hline & LJU & $10-14$ & 14 & 12.42 & 12.32 & 3.28 & $4.46-17.22$ \\
\hline & LQJ & $13-18$ & 6 & 11.15 & 10.66 & 2.38 & $8.26-14.45$ \\
\hline & $\mathbf{L Q U}$ & $19-25$ & 14 & 19.83 & 19.35 & 3.51 & $15.21-26.30$ \\
\hline & LPO & $6-13$ & 17 & 17.54 & 15.72 & 4.12 & $11.51-24.59$ \\
\hline & LSQ & $20-21$ & 11 & 11.71 & 11.08 & 3.07 & $8.24-16.57$ \\
\hline & WPF & $4-5$ & 18 & 7.17 & 7.15 & 1.66 & $3.97-11.27$ \\
\hline & WFR & $7-8$ & 18 & 10.55 & 10.61 & 1.88 & $7.02-13.55$ \\
\hline & WPA & $12-16$ & 12 & 22.53 & 22.94 & 2.94 & $17.41-26.85$ \\
\hline & SMX & $11-11$ & 15 & 47.85 & 46.35 & 7.63 & $39.24-66.10$ \\
\hline & WVO & $28-28$ & 10 & 4.01 & 3.74 & 1.38 & $2.43-7.23$ \\
\hline & WCO & $28-34$ & 9 & 7.00 & 6.61 & 1.39 & $5.23-9.10$ \\
\hline & WPAL & $29-35$ & 14 & 18.08 & 18.23 & 2.37 & $15.24-21.50$ \\
\hline
\end{tabular}




\begin{tabular}{|c|c|c|c|c|c|c|}
\hline & WBS & $33-33$ & $19 \quad 15.35$ & 14.71 & 2.19 & $12.07-20.05$ \\
\hline & WMX & $10-11$ & 9.80 & 9.84 & 2.24 & $6.48-14.27$ \\
\hline & WJU & $14-15$ & 7.26 & 7.28 & 2.19 & 4.11-10.14 \\
\hline & WQJ & $16-25$ & 16.35 & 17.81 & 4.03 & $9.91-21.21$ \\
\hline & WPO & $13-14$ & 5.15 & 5.00 & 1.83 & $2.73-9.05$ \\
\hline & WOP & $20-22$ & 11.41 & 10.96 & 3.54 & $7.78-17.73$ \\
\hline & CHARACTERS & $\mathbf{N}$ & MEAN & Median & SD & Min-MaX \\
\hline & LPF/TLS & 9 & 0.13 & 0.13 & 0.04 & $0.05-0.19$ \\
\hline & LFR/TLS & 11 & 0.19 & 0.18 & 0.02 & $0.17-0.22$ \\
\hline & LPA/TLS & 8 & 0.51 & 0.49 & 0.08 & $0.45-0.65$ \\
\hline & LVO/TLS & 8 & 0.11 & 0.12 & 0.03 & $0.06-0.15$ \\
\hline & LPAL/TLS & 10 & 0.11 & 0.11 & 0.03 & $0.06-0.17$ \\
\hline$\underline{x}$ & LPT/TLS & 12 & 0.18 & 0.18 & 0.02 & $0.13-0.22$ \\
\hline 占 & LBS/TLS & 12 & 0.21 & 0.21 & 0.02 & $0.17-0.24$ \\
\hline 될 & LBO/TLS & 11 & 0.24 & 0.24 & 0.02 & $0.21-0.26$ \\
\hline 獣 & LMX/TLS & 11 & 0.29 & 0.28 & 0.06 & $0.17-0.38$ \\
\hline$\frac{1}{6}$ & LJU/TLS & 8 & 0.21 & 0.21 & 0.05 & $0.15-0.29$ \\
\hline 台 & LQJ/TLS & 5 & 0.18 & 0.16 & 0.05 & $0.14-0.25$ \\
\hline 光 & LQU/TLS & 10 & 0.30 & 0.30 & 0.04 & $0.23-0.37$ \\
\hline 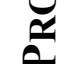 & LPO/TLS & 11 & 0.29 & 0.29 & 0.03 & $0.23-0.35$ \\
\hline & LSQ/TLS & 7 & 0.19 & 0.20 & 0.05 & $0.12-0.24$ \\
\hline & WPF/TWS & 13 & 0.12 & 0.12 & 0.02 & $0.08-0.15$ \\
\hline & WFR/TWS & 13 & 0.17 & 0.17 & 0.02 & $0.14-0.21$ \\
\hline & WPA/TWS & 10 & 0.37 & 0.37 & 0.05 & $0.29-0.44$ \\
\hline
\end{tabular}




\begin{tabular}{ccccccc}
\hline SMX/TWS & 12 & 0.75 & 0.76 & 0.06 & $0.67-0.86$ \\
\hline WVO/TWS & 7 & 0.09 & 0.07 & 0.02 & $0.04-0.09$ \\
\hline WCO/TWS & 7 & 0.11 & 0.12 & 0.02 & $0.09-0.13$ \\
\hline WPAL/TWS & 9 & 0.29 & 0.29 & 0.02 & $0.27-0.32$ \\
\hline WBS/TWS & 12 & 0.24 & 0.24 & 0.02 & $0.22-0.28$ \\
\hline WMX/TWS & 12 & 0.16 & 0.15 & 0.04 & $0.08-0.24$ \\
\hline WJU/TWS & 6 & 0.12 & 0.13 & 0.05 & $0.05-0.17$ \\
\hline WPO/TWS & 12 & 0.08 & 0.08 & 0.02 & $0.06-0.13$ \\
\hline WOP/TWS & 11 & 0.18 & 0.17 & 0.04 & $0.13-0.23$ \\
\hline
\end{tabular}

1 SD: standard deviation values. N: number of entries. Max-Min: maximum and minimum values.

2 a straight line between two landmarks used to trace linear measurements (see figure 2 to visualize 3 the landmarks). 


\section{Table 3(on next page)}

PCA loadings: raw data.

Loading values of characters in the raw data matrix related to the first three principal components in PCA, comparing the Mean Value (mv) approach with the Iterative Imputation (ii) approach. 


\begin{tabular}{|c|c|c|c|c|c|c|}
\hline Char. & PC1 (mv) & PC2 (mv) & PC3 (mv) & PC1 (ii) & PC2 (ii) & PC3 (ii) \\
\hline LPF & -0.05 & 0.04 & 0.02 & -0.04 & -0.05 & -0.05 \\
\hline WPF & 0.14 & 0.02 & 0.05 & -0.001 & 0.12 & 0.08 \\
\hline LFR & 0.19 & -0.01 & -0.09 & 0.02 & 0.14 & -0.04 \\
\hline WFR & 0.17 & 0.10 & -0.02 & 0.01 & 0.13 & -0.001 \\
\hline LPA & 0.27 & 0.74 & 0.10 & 0.89 & 0.04 & 0.11 \\
\hline WPA & 0.12 & 0.17 & -0.01 & 0.22 & 0.16 & 0.06 \\
\hline SMX & 0.66 & -0.45 & -0.22 & 0.01 & 0.59 & -0.34 \\
\hline LVO & 0.05 & 0.07 & 0.03 & -0.02 & 0.11 & 0.01 \\
\hline WVO & 0.04 & 0.03 & -0.07 & 0.02 & 0.09 & -0.11 \\
\hline WCO & 0.05 & 0.04 & -0.07 & 0.03 & 0.12 & -0.08 \\
\hline LPAL & 0.08 & 0.04 & 0.06 & 0.04 & 0.13 & 0.27 \\
\hline WPAL & 0.15 & 0.02 & -0.09 & 0.03 & 0.23 & -0.05 \\
\hline LPT & 0.17 & -0.14 & 0.08 & -0.02 & 0.13 & 0.10 \\
\hline LBS & 0.14 & -0.02 & 0.01 & 0.01 & 0.10 & 0.05 \\
\hline WBS & 0.12 & 0.05 & -0.07 & 0.02 & 0.19 & -0.05 \\
\hline LBO & 0.11 & 0.11 & -0.07 & 0.03 & 0.20 & 0.03 \\
\hline LMX & 0.18 & -0.17 & 0.68 & -0.18 & 0.16 & 0.38 \\
\hline WMX & 0.09 & -0.07 & 0.25 & -0.08 & 0.11 & 0.19 \\
\hline LJU & 0.08 & 0.13 & 0.30 & -0.14 & 0.19 & 0.25 \\
\hline WJU & -0.01 & 0.02 & 0.10 & 0.01 & -0.01 & 0.21 \\
\hline LQJ & 0.04 & -0.05 & -0.04 & -0.16 & 0.18 & -0.11 \\
\hline WQJ & 0.03 & 0.07 & 0.29 & -0.11 & 0.17 & 0.42 \\
\hline LQU & 0.18 & -0.13 & 0.32 & -0.13 & 0.21 & 0.18 \\
\hline LPO & 0.36 & 0.19 & -0.13 & 0.03 & 0.29 & 0.02 \\
\hline WPO & 0.11 & -0.04 & 0.05 & -0.01 & 0.10 & 0.04 \\
\hline WOP & 0.21 & 0.15 & -0.23 & 0.06 & 0.30 & -0.24 \\
\hline LSQ & 0.07 & 0.19 & 0.11 & 0.16 & 0.02 & 0.43 \\
\hline
\end{tabular}

1 Char: characters. mv: Mean Value approach. ii: Iterative Imputation approach. 


\section{Table 4 (on next page)}

PCA loadings: proportion data.

Loading values of characters in the proportions data matrix related to the first two principal components in PCA, comparing the Mean Value (mv) approach with the Iterative Imputation (ii) approach. 


\begin{tabular}{|c|c|c|c|c|}
\hline Char. & PC1 (mv) & PC2 (mv) & PC1 (ii) & PC2 (ii) \\
\hline LPF/TLS & 0.003 & -0.13 & 0.11 & -0.30 \\
\hline LFR/TLS & 0.001 & -0.04 & 0.03 & -0.02 \\
\hline LPA/TLS & 0.28 & 0.66 & -0.13 & 0.67 \\
\hline LVO/TLS & -0.002 & 0.05 & -0.03 & -0.02 \\
\hline LPAL/TLS & 0.08 & 0.02 & 0.07 & 0.12 \\
\hline LPT/TLS & -0.05 & -0.10 & -0.02 & -0.01 \\
\hline LBS/TLS & 0.03 & -0.17 & 0.11 & -0.10 \\
\hline LBO/TLS & -0.02 & -0.04 & 0.01 & -0.04 \\
\hline LMX/TLS & 0.38 & -0.43 & 0.48 & -0.18 \\
\hline LJU/TLS & 0.16 & 0.01 & 0.16 & 0.14 \\
\hline LQJ/TLS & 0.06 & -0.09 & 0.21 & -0.17 \\
\hline LQU/TLS & 0.27 & -0.07 & 0.28 & 0.05 \\
\hline LPO/TLS & -0.16 & 0.13 & -0.18 & 0.03 \\
\hline LSQ/TLS & 0.16 & 0.23 & 0.20 & 0.34 \\
\hline WPF/TWS & 0.07 & 0.09 & -0.001 & 0.11 \\
\hline WFR/TWS & 0.07 & 0.13 & 0.02 & 0.05 \\
\hline WPA/TWS & 0.23 & 0.32 & 0.08 & 0.33 \\
\hline SMX/TWS & 0.38 & -0.12 & 0.33 & -0.01 \\
\hline WVO/TWS & -0.05 & -0.04 & -0.04 & -0.10 \\
\hline WCO/TWS & -0.04 & 0.07 & -0.11 & 0.04 \\
\hline WPAL/TWS & 0.04 & -0.07 & 0.04 & -0.003 \\
\hline WBS/TWS & 0.03 & -0.05 & 0.02 & -0.03 \\
\hline WMX/TWS & 0.35 & -0.05 & 0.30 & 0.03 \\
\hline WJU/TWS & 0.18 & 0.01 & 0.26 & 0.19 \\
\hline WQJ/TWS & 0.48 & -0.003 & 0.41 & 0.20 \\
\hline WPO/TWS & 0.02 & 0.01 & -0.01 & 0.07 \\
\hline WOP/TWS & -0.13 & 0.27 & -0.21 & 0.09 \\
\hline
\end{tabular}

1 Char: characters. mv: Mean Value approach. ii: Iterative Imputation approach. 